\title{
Circadian transcriptome analysis in human fibroblasts from Hunter syndrome and impact of iduronate-2-sulfatase treatment
}

Gianluigi Mazzoccoli ${ }^{{ }^{*}+}$, Rosella Tomanin ${ }^{2}$, Tommaso Mazza ${ }^{3+}$, Francesca D'Avanzo ${ }^{2}$, Marika Salvalaio ${ }^{2}$, Laura Rigon², Alessandra Zanetti ${ }^{2}$, Valerio Pazienza ${ }^{4 \dagger}$, Massimo Francavilla ${ }^{5}$, Francesco Giuliani ${ }^{5}$, Manlio Vinciguerra ${ }^{6}$ and Maurizio Scarpa ${ }^{2,7}$

\begin{abstract}
Background: Hunter syndrome (HS) is a lysosomal storage disease caused by iduronate-2-sulfatase (IDS) deficiency and loss of ability to break down and recycle the glycosaminoglycans, heparan and dermatan sulfate, leading to impairment of cellular processes and cell death. Cell activities and functioning of intracellular organelles are controlled by the clock genes (CGs), driving the rhythmic expression of clock controlled genes (CCGs). We aimed to evaluate the expression of CGs and downstream CCGs in HS, before and after enzyme replacement treatment with IDS.
\end{abstract}

Methods: The expression levels of CGs and CCGs were evaluated by a whole transcriptome analysis through Next Generation Sequencing in normal primary human fibroblasts and fibroblasts of patients affected by HS before and $24 \mathrm{~h} / 144 \mathrm{~h}$ after IDS treatment. The time related expression of CGs after synchronization by serum shock was also evaluated by qRT-PCR before and after 24 hours of IDS treatment.

Results: In HS fibroblasts we found altered expression of several CGs and CCGs, with dynamic changes $24 \mathrm{~h}$ and $144 \mathrm{~h}$ after IDS treatment. A semantic hypergraph-based analysis highlighted five gene clusters significantly associated to important biological processes or pathways, and five genes, AHR, HIF1A, CRY1, ITGA5 and EIF2B3, proven to be central players in these pathways. After synchronization by serum shock and $24 \mathrm{~h}$ treatment with IDS the expression of ARNTL2 at $10 \mathrm{~h}(\mathrm{p}=0.036)$, PER1 at $4 \mathrm{~h}(\mathrm{p}=0.019)$, PER2 at $10 \mathrm{~h}(\mathrm{p}=0.041)$ and $16 \mathrm{~h}(\mathrm{p}=0.043)$ changed in HS fibroblasts.

Conclusion: CG and CCG expression is altered in HS fibroblasts and IDS treatment determines dynamic modifications, suggesting a direct involvement of the CG machinery in the physiopathology of cellular derangements that characterize HS.

Keywords: Clock gene, Hunter syndrome, Lysosomal storage disease, Circadian rhythm

\section{Background}

Hunter syndrome (HS), or Mucopolysaccharidosis type II, is a lysosomal storage disease and a $\mathrm{X}$-linked recessive genetic disorder caused by a mutation in the IDS gene, leading to absence or deficiency of the enzyme iduronate2-sulfatase (IDS). IDS deficit interferes with the ability to

\footnotetext{
*Correspondence: g.mazzoccoli@operapadrepio.it

${ }^{\dagger}$ Equal contributors

'Department of Medical Sciences, Division of Internal Medicine and Chronobiology Unit, IRCCS Scientific Institute and Regional General Hospital "Casa Sollievo della Sofferenza", S.Giovanni Rotondo (FG), Italy Full list of author information is available at the end of the article
}

break down and recycle glycosaminoglycans (GAGs), precisely dermatan sulfate and heparan sulfate, causes lysosomal engulfment, and hinders the customary working of cellular functions, compromising anatomical integrity in a number of organ systems and leading to curtailment of life expectancy [1]. The patients are characterized by coarsening of facial features, bone and joint abnormalities, short stature, changes in the heart, respiratory system, hearing and vision, and in more severe forms by disturbed motor function, progressive learning difficulties and behavioural abnormalities [2]. Enzyme replacement therapy

\section{Biomed Central}

(c) 2013 Mazzoccoli et al.; licensee BioMed Central Ltd. This is an Open Access article distributed under the terms of the Creative Commons Attribution License (http://creativecommons.org/licenses/by/2.0), which permits unrestricted use, distribution, and reproduction in any medium, provided the original work is properly cited. 
with idursulfase, a recombinant form of human IDS, represents the only affordable therapeutic approach presently.

The cellular processes in every life form from bacteria to humans show diurnal variations driven by an internal timing system, and the oscillation frequency has a near24-hour period, so that the rhythmicity is defined circadian (from the latin circa, about, and dies, a day) [3-5]. The mammalian circadian timing system is composed by a central pacemaker and master oscillator in the suprachiasmatic nuclei $(\mathrm{SCN})$ of the brain and self-sustained oscillators in the peripheral tissues [6,7]. The SCN are entrained to the environmental light/dark cycle by cues perceived through photon capture, signalling by melanopsin-containing retinal ganglion cells, and inputs conveyed by the retino-hypothalamic tract [8]. They synchronize peripheral oscillators and coordinate bodily functions by means of output pathways that may be neural projections (sympathetic and parasympathetic nerve fibers) or diffusible factors (for example hormones as cortisol and melatonin) $[9,10]$.

The molecular mechanisms underlying the biological clock functioning consist of a transcriptional-translational feedback loop operated by a set of genes, called core clock genes, coding for proteins that in turn block gene expression, completing a cycle in approximately 24 hours [11]. The positive limb of the loop is represented by the CLOCK (or its paralog NPAS2) and ARNTL/BMAL1 (or its paralog ARNTL2/BMAL2) genes that code for the transcription factors CLOCK/NPAS2 and ARNTL/2. A heterodimer of the CLOCK/NPAS2 and ARNTL/2 proteins rhythmically activates the transcription of clock genes PER1, PER2, PER3, CRY1, CRY2, coding for PER and CRY proteins that represent the negative limb of the loop. PER and CRY proteins along with Casein Kinase I $\delta / \varepsilon(C K I \delta / \varepsilon)$ and Casein Kinase II (CKII A1, A2, B), responsible of multilevel posttranslational regulation of various clock components, cooperate to form a repression complex that translocates back into the nucleus, interacts directly with CLOCK/NPAS2 and ARNTL/2, and impede their transcriptional activity [12]. The clock gene machinery is connected to a supporting feedback loop operated by the nuclear receptors REV-ERB $\alpha / \beta$ (encoded by the genes NR1D1 and NR1D2) and retinoic acid-related orphan receptor (ROR) $\alpha / \gamma$, where RORs positively regulate $A R N T L / 2$ and $R E V$ $E R B$ expression and, in turn, REV-ERBs antagonize RORs $[13,14]$. Besides, SIRT1, a NAD +-dependent protein and histone deacetylase, is required for high-magnitude circadian transcription of several core clock genes, including ARNTL, PER2, and CRY1. SIRT1 counterbalances the histone acetyltransferase activity of CLOCK, binds CLOCK-ARNTL heterodimer in a circadian manner and promotes the deacetylation and degradation of PER2 [15].
TIMELESS is a core circadian clock gene in Drosophila melanogaster and is maintained in mammals, but its role in mammalian circadian clock function is not clear. TIMELESS and its partner TIMELESS interacting protein (TIPIN) interact with components of the DNA replication system to regulate DNA replication processes under both normal and stress conditions and are essential for ataxia telangiectasia and Rad3-related (ATR)-checkpoint kinase (Chk)1 and ataxia telangiectasia mutated (ATM)-checkpoint kinase (Chk)2-mediated signaling and S-phase arrest [16-19].

The clock gene oscillation drives the rhythmic expression of other genes defined clock controlled genes, for example DBP, TEF, HLF, HSF1, NFIL3 (also called E4BP4), DEC1-2 (also called BHLHE40-41), which steer downstream tissue specific genes regulating key cellular functions, such as cell cycle progression, proliferation, DNA damage response, autophagy, apoptosis, metabolism, redox equilibrium [20-23], and are involved in physiological processes such as inflammation/immune response $[24,25]$, and paraphysiological phenomena, such as aging [26]. About 5\% to $15 \%$ of genome-wide mRNA expression exhibits a circadian rhythm that is driven by the clock genes and there is a tissue specificity of cycling genes and a tissue specificity of clock controlled gene expression timing and level (output genes i.e., genes involved in the functional output of an organ) [27-30]. Accordingly, multicellular organisms are characterized by tissue-specific circadian regulation of transcription, with peripheral oscillators controlling the definite biochemical cascades relevant to their tissue or organ function and generating rhythms in various pathways, including those involved in intracellular activities and depending on the correct functioning of intracellular organelles [27-30].

The importance of the role played by the clock gene machinery in the regulation of the processes in the intracellular organelles is confirmed by the physiopathology of Niemann-Pick types A and B disease, related to deficit of sphingomyelin synthase 2 (SGMS2), the enzyme that catalyzes the transfer of phosphocholine from phosphatidylcholine onto ceramide to produce sphingomyelin, a major component of cell and Golgi membranes. Furthermore, Niemann-Pick type $\mathrm{C}$ disease is related to deficit of Niemann-Pick C1 (NPC1), which is crucial for the intracellular trafficking of cholesterol from the late endosome to the trans-Golgi network [31]. SGMS2 and NPC1protein levels oscillate with circadian rhythmicity driven by the clock controlled genes SGMS2 and NPC1 respectively $[27,28]$. Patients carrying a mutation in these genes develop a condition characterized by accumulation of sphingomyelin in spleen, liver, lungs, bone marrow and brain, causing irreversible neurological damage, and high cholesterol levels in the endosomal-lysosomal system, respectively [32].

The aim of our study was to assess the expression of clock genes and clock controlled genes in Mucopolysaccharidosis 
type II, and to evaluate the circadian pattern of variation and the effects of the treatment with idursulfase on the expression of clock genes and clock controlled genes at different time points.

We addressed these issues taking advantage of an in vitro model of HS, represented by human fibroblasts with the mutational features of this mucopolysaccharidosis, through evaluation of the mRNA expression levels of the core clock genes and of a panel of clock controlled genes selected by means of literature-mining [27-30,33] (for a complete list of circadian transcripts refer to: CircaDB at http://circadb. org). These evaluations are part of a whole transcriptome analysis performed by Next Generation Sequencing (NGS) in fibroblasts from healthy subjects and fibroblasts from HS patients before, 24 hours and 144 hours after idursulfase treatment. We also evaluated by qRT-PCR the expression levels of core clock genes upon serum-shock induced synchronization in normal human fibroblasts and fibroblasts of patients affected by HS before and after 24 hours of treatment with idursulfase.

\section{Materials and methods \\ Cells}

Human fibroblasts from skin biopsy of five HS paediatric patients carrying different mutation in IDS gene were obtained from "Cell Line and DNA Bank from Patients Affected by Genetic Diseases", Gaslini Institute (Genoa, Italy). As healthy controls human fibroblasts from four children's circumcision were used; they were obtained from the Histology Unit of the Department of Histology, Microbiology and Medical Biotechnology (University of Padua, Padua, Italy). Written informed consents were obtained from patients at the time of biopsy and the study was approved by the Ethics Committee of the University of Padua, Padua, Italy. All cells were anonymously obtained.

\section{Cell culture and treatment with idursulfase of HS fibroblasts}

Primary fibroblasts were cultured at $37^{\circ} \mathrm{C}$ in $5 \% \mathrm{CO} 2$ atmosphere in RPMI medium supplemented with $15 \%$ fetal bovine serum (FBS), $100 \mathrm{U} / \mathrm{ml}$ penicillin and $100 \mathrm{ng} / \mathrm{ml}$ streptomycin (Invitrogen Life Technologies, Milan, Italy). Fibroblasts of patients affected by HS were treated with idursulfase (Elaprase ${ }^{\circledR}$, Shire Human Genetic Therapies, Inc, Lexington, MA, USA) at a concentration of $62.5 \mathrm{nM}$ for 24 hours and the cells were harvested $24 \mathrm{~h}$ and $144 \mathrm{~h}$ after idursulfase treatment.

\section{Whole transcriptome analysis performed by NGS technology}

Total RNA was extracted using the TRIzol ${ }^{\circledR}$ Reagent (Sigma-Aldrich ${ }^{\circledR}$ ) according to the manufacturer's protocols. Isolated RNA was quantified by NanoDrop ND-
1000 Spectrophotometer (Thermo Scientific, Barnstead, $\mathrm{NH}$, USA) and further assessed for quality using the Agilent 2100 Bioanalyzer (Santa Clara, CA) prior to library construction. Total RNAs extracted from different cell lines were equally pooled into two specimens (Hunter and healthy) using $12.5 \mu \mathrm{g}$ of RNA from each cell line. From total RNA of each pool mRNA purification was performed trough poliA(+) enrichment by Dynabeads $^{\circledR}$ mRNA Purification Kit (Life Technologies ${ }^{\text {TM }}$ Carlsbad, CA, USA). Total RNA was used for standard fragment-library preparation using the SOLiD Total RNA-Seq Kit (Life Technologies). Finally, emulsion PCR reactions were carried out by mixing appropriated amount of libraries with SOLiD beads. After PCR amplification, emulsions were broken using butanol, and the beads were washed, enriched, and terminal transferased before quantification and deposition onto a slide for sequencing. Templated beads were deposited onto one full slide, one sample for quarter (quad). Sequencing was carried out to 35 bases using $\mathrm{SOLiD}^{\text {тм }} 3$ (Sequencing by Oligo Ligation and Detection) System and following the manufacturer's instructions.

\section{Alignment}

Reads obtained from sequencing were aligned on human genome by CRIBI Biotechnology Centre (University of Padova) using the PASS software (http://pass.cribi.unipd.it). The February 2009 human genome assembly (GRCh37), publicly available at UCSC Genome Bioinformatics Site (http://genome.ucsc.edu/) was taken as reference sequence and the options best-hit, gap $=0$ and maximun mismach $=3$ have been selected. Only unique reads (aligning on only one gene) and only genes with coverage higher than 50\% of gene length were considered.

\section{Serum-shock induced synchronization and treatment with idursulfase of HS fibroblasts}

The serum shock induced synchronization was performed as follows: approximately $4 \times 10^{5}$ cells/ 6 wells were plated the day before the experiments. Fibroblasts of patients affected by HS were treated with idursulfase at a concentration of $62.5 \mathrm{nM}$ for 24 hours (Elaprase, Shire Human Genetic Therapies, Inc, Lexington, MA, USA). The day of the experiments, culture medium was exchanged with serum-rich medium (RPMI containing $50 \%$ FBS) and after 2 hours this medium was replaced with serum free RPMI [34]. The cells were harvested $1 \mathrm{~h}, 4 \mathrm{~h}, 10 \mathrm{~h}, 16 \mathrm{~h}, 22 \mathrm{~h}$ and $28 \mathrm{~h}$ after serum shock.

\section{Quantitative real time polymerase chain reaction (qRT-PCR)}

Total RNA was extracted from normal primary human fibroblasts and fibroblasts of patients affected by HS before and after 24 hours of idursulfase treatment at the indicated 
time points using the RNeasy ${ }^{\circledR}$ Mini Kit (Qiagen S.p.a. Milan, Italy) and subsequently digested by DNase I. Quantitative Real Time PCR was performed starting from $100 \mathrm{ng}$ of purified RNA using the one step quantifast SYBR Green RT PCR KIT (Qiagen). For real-time PCR, we used the following SYBR Green QuantiTect Primers purchased from Qiagen: ARNTL (QT00068250), ARNTL2 (QT00011844), CLOCK (QT00054481), CRY1 (QT00025067) PER1 (QT00069265), PER2 (QT00011207), PER3 (QT00097713). Expression levels of target gene were normalized using the housekeeping control gene TATA binding protein (TBP, QT00000721). Values of mRNA expression levels of clock genes were calculated using the formula $2^{-\Delta \Delta C t}$.

\section{Statistical analysis}

Results are expressed as means \pm SE of at least three different experiments. Comparisons were made using Student's t-test as appropriate. The limit of statistical significance was set at to $\mathrm{p}<0.001$ for comparisons of levels of mRNA expression determined by NGS, and $\mathrm{p}<0.05$ for comparisons of levels of mRNA expression determined by qRT-PCR. Each time series of clock gene expression levels was analyzed for circadian rhythm characteristics by the single cosinor procedure involving the fit of a 24-h cosine curve to the data by least squares linear regression, in order to accurately describe waveforms and rhythm characteristics. An $\mathrm{R} 2$ value and a $\mathrm{p}$ value for the rejection of the zeroamplitude assumption were determined for each component in the cosine model separately and overall, with rhythm detection considered statistically significant if $\mathrm{p} \leq 0.05$ and borderline significant if $\mathrm{p}>0.05$ and $\mathrm{p}<0.10$ for any period tested. Circadian (24-h) characteristics were summarized from the 24-h cosine. Rhythm characteristics determined from the best-fitting cosine model include the MESOR (the middle of the cosine representing an adjusted average if unequal sampling), the amplitude (half the distance from the peak and trough of the best fitting curve), and the acrophase of the cosine model (the peak of a single component cosine). All analyses were performed using the MATLAB 6.5 statistical package (MathWorks, Natick, MA, USA).

\section{Results}

The mRNA expression levels of the core clock genes ARNTL, ARNTL2, CLOCK, CRY1, CRY2, CSNK1D, CSNK1E, CSNK2A1, CSNK2A2, CSNK2B, NPAS2, NR1D1, NR1D2, PER1, PER2, PER3, RORA, SIRT1, TIMELESS, TIPIN and of a set of clock controlled genes were evaluated as part of a whole transcriptome analysis performed by NGS technology in healthy human fibroblasts (C) and fibroblasts of HS patients before (H), 24 hours (T1) and 144 hours (T2) after idursulfase treatment. Ratio, log2 (ratio), fold change and p-values are shown in Additional file 1: Table S1.
The expression levels of ARNTL, ARNTL2, CLOCK, CRY1, PER1, PER2, and PER3 were also evaluated by qRT-PCR after serum-shock induced synchronization in normal human fibroblasts and fibroblasts of patients affected by HS before and after 24 hours of treatment with idursulfase.

\section{Evaluation by NGS technology of core clock gene expression in $\mathrm{HS}$ fibroblasts vs healthy fibroblasts (H vs C)} In HS fibroblasts the genes CLOCK (fold change $=-1.45$, $\mathrm{p}<0.0001$ ), NPAS2 (fold change $=-1.65, \mathrm{p}<0.0001$ ), CRY1 (fold change $=-1.51, \mathrm{p}<0.0001$ ), NR1D2 (fold change $=-1.97, \mathrm{p}<0.0001$ ) and SIRT1 (fold change $=-1.30$, $\mathrm{p}<0.0001$ ) showed lower expression levels compared to healthy controls. Conversely the genes PER1 (fold change = 1.27, $\mathrm{p}<0.0001$ ), CSNK1D (fold change $=1.26, \mathrm{p}<0.0001$ ), CSNK1E (fold change $=1.54, \mathrm{p}<0.0001$ ), and NR1D1 (fold change $=1.99, \mathrm{p}<0.0001$ ) showed higher expression levels in HS fibroblasts. The expression level of $A R N T L$ (fold change $=1.34, \mathrm{p}=0.01)$, ARNTL2 (fold change $=$ 1.09, $\mathrm{p}=0.47$ ), PER2 (fold change $=1.40, \mathrm{p}=0.001$ ), PER3 (fold change $=-1.01, \mathrm{p}=0.79), C R Y 2($ fold change $=1.16$, $\mathrm{p}=0.02$ ), CSNK2A1 (fold change $=1.02, \mathrm{p}=0.56$ ), CSNK2A2 (fold change $=-1.08, \mathrm{p}=0.26$ ), RORA (fold change $=-1.07, \mathrm{p}=0.28)$, TIMELESS (fold change $=1.25$, $\mathrm{p}=0.006$ ), and TIPIN (fold change $=-1.25 ; \mathrm{p}=0.27$ ) was not different in a statistically significant way between normal and HS fibroblasts or did not reach the $\mathrm{p}<0.001$ threshold value.

\section{Evaluation by NGS technology of core clock gene expression levels in HS fibroblasts after 24 hours of treatment with idursulfase versus healthy fibroblasts (T1 vs C)}

In HS fibroblasts after 24 hours of treatment with idursulfase NPAS2 (fold change $=-1.39, \mathrm{p}=0.0005$ ), CRY1 (fold change $=-1.75, \mathrm{p}<0.0001$ ) and NR1D2 (fold change $=-1.65, \mathrm{p}<0.0001)$ genes showed lower expression levels in comparison to controls. The genes $A R N T L$ (fold change $=1.53, \mathrm{p}<0.0001)$, ARNTL2 (fold change $=$ 2.22, $\mathrm{p}<0.0001$ ), PER2 (fold change $=1.72$, $\mathrm{p}<0.0001$ ), CSNK1E (fold change $=1.47, \mathrm{p}<0.0001$ ), CSNK2B (fold change $=1.15, \mathrm{p}<0.0001)$, NR1D1 (fold change $=3.59$, $\mathrm{p}<0.0001$ ), and TIMELESS (fold change $=2.41, \mathrm{p}<0.0001$ ) showed higher expression levels in HS fibroblasts after $24 \mathrm{~h}$ treatment, in comparison to healthy human fibroblasts.

The expression level of CLOCK (fold change $=-1.13$, $\mathrm{p}=0.003$ ), PER1 (fold change $=1.22, \mathrm{p}=0.004$ ), PER3 (fold change $=1.14, \mathrm{p}=0.03$ ), CRY2 (fold change $=1.04$, $\mathrm{p}=0.55$ ), CSNK $2 A 1$ (fold change $=1.04, \mathrm{p}=0.30$ ), CSNK1D (fold change $=1.12, \mathrm{p}=0.007), C S N K 2 A 2$ (fold change $=-1.09, \mathrm{p}=0.25), R O R A$ (fold change $=-1.14$, $\mathrm{p}=0.03$ ), SIRT1 (fold change $=-1.12, \mathrm{p}=0.07$ ) and TIPIN (fold change $=1.4 ; \mathrm{p}=0.03$ ) was not different in a 
statistically significant way between normal and idursulfase treated HS fibroblasts or did not reach the $\mathrm{p}<$ 0.001 threshold value.

\section{Evaluation by NGS technology of core clock gene expression levels in HS fibroblasts 144 hours after treatment with idursulfase versus healthy fibroblasts (T2 vs C)}

In HS fibroblasts 144 hours after treatment with idursulfase the genes CLOCK (fold change $=-1.66$, $\mathrm{p}<0.0001$ ), NPAS2 (fold change $=-1.56, \mathrm{p}<0.0001$ ), CRY1 (fold change $=-2.00, \mathrm{p}<0.0001$ ), NR1D2 (fold change $=-2.53, \mathrm{p}<0.0001), R O R A$ (fold change $=-1.28$, $\mathrm{p}=0.0003$ ), TIMELESS (fold change $=-1.93$, $\mathrm{p}<0.0001$ ) and SIRT1 (fold change $=-1.41, \mathrm{p}<0.0001$ ) showed lower expression levels in comparison to controls. CSNK1E (fold change $=1.27, \mathrm{p}<0.0001$ ), and NR1D1 (fold change $=1.72, \mathrm{p}<0.0001$ ) showed higher expression levels in HS fibroblasts 144 hours after idursulfase treatment in comparison to healthy human fibroblasts. The expression level of $A R N T L$ (fold change $=1.38, \mathrm{p}=0.007$ ), ARNTL2 (fold change $=-1.36, \mathrm{p}=0.03$ ), PER1 (fold change $=1.02, \mathrm{p}=0.70)$, PER2 $(($ fold change $=1.20$ $\mathrm{p}=0.10)$, PER3 (fold change $=-1.08, \mathrm{p}=0.25$ ), CRY2 (fold change $=1.05, \mathrm{p}=0.48$ ), CSNK1D (fold change $=1.11, \mathrm{p}=0.01), C S N K 2 A 1$ (fold change $=-1.14$, $\mathrm{p}=0.02), C S N K 2 A 2$ (fold change $=-1.29, \mathrm{p}=0.002$ ), CSNK2B (fold change $=1.00, \mathrm{p}=0.85$ ), and TIPIN (fold change $=-1.64 ; \mathrm{p}=0.03)$ was not different in a statistically significant way between normal and idursulfase treated HS fibroblasts or did not reach the $\mathrm{p}<0.001$ threshold value.

Evaluation by NGS technology of changes of clock gene expression levels in HS fibroblasts after 24 hours of treatment with idursulfase versus untreated HS fibroblasts (T1 vs $\mathrm{H}$ )

In HS fibroblasts after 24 hours of treatment with IDS $C S N K 2 B$ (fold change $=-1.60, \mathrm{p}<0.0001$ ) showed lower expression levels compared to untreated HS fibroblasts $(\mathrm{H})$. Conversely the genes CLOCK (fold change $=1.28$, $\mathrm{p}<0.0001$ ), ARNTL2 (fold change $=2.03, \mathrm{p}<0.0001$ ), NR1D1 (fold change $=1.80, \mathrm{p}<0.0001$ ), NR1D2 (fold change $=1.19, \mathrm{p}<0.001$ ), and TIMELESS (fold change $=$ 1.91, $\mathrm{p}<0.0001$ ) showed higher expression levels in HS fibroblasts treated for 24 hours with idursulfase, in comparison to untreated HS fibroblasts. The expression level of NPAS2 (fold change $=1.18, \mathrm{p}=0.11$ ), ARNTL1 (fold change $=1.14, \mathrm{p}=0.21)$, PER1 (fold change $=-1.04$, $\mathrm{p}=0.50$ ), PER2 (fold change $=1.23, \mathrm{p}=0.02)$, PER3 (fold change $=1.16, \mathrm{p}=0.02), C R Y 1$ (fold change $=-1.16, \mathrm{p}=$ 0.09 ), CRY2 (fold change $=-1.11, \mathrm{p}=0.11$ ), CSNK1D (fold change $=-1.12, \mathrm{p}=0.05), C S N K 1 E$ (fold change $=-1.05$, $\mathrm{p}=0.20), \operatorname{CSNK} 2 A 1$ (fold change $=1.01, \mathrm{p}=0.66$ ),
CSNK2A2 (fold change $=-1.00, \mathrm{p}=0.98$ ), RORA (fold change $=-1.07, \mathrm{p}=0.30$ ), SIRT1 (fold change $=1.16$, $\mathrm{p}=0.04$ ), and TIPIN (fold change $=1.83 ; \mathrm{p}=0.01$ ) was not different in a statistically significant way between treated and not treated HS fibroblasts or did not reach the $\mathrm{p}<0.001$ threshold value.

\section{Evaluation by NGS technology of changes of clock gene expression levels in HS fibroblasts after 144 hours of treatment with idursulfase versus untreated HS fibroblasts (T2 vs $\mathrm{H}$ )}

In HS fibroblasts after 144 hours of treatment with IDS the genes CSNK1E (fold change $=-1.12, \mathrm{p}<0.0001$ ), CSNK2A1 (fold change $=-1.17, \mathrm{p}<0.001$ ), CSNK2B (fold change $=-1.21, \mathrm{p}<0.0001$ ), NR1D2 (fold change $=-1.28, \mathrm{p}<0.0001$ ), and TIMELESS (fold change $=-2.4, \mathrm{p}<0.0001)$ showed lower expression levels, in comparison to untreated HS fibroblasts.

The expression level of CLOCK (fold change $=-1.14$, $\mathrm{p}=0.009$ ), NPAS2 (fold change $=1.05, \mathrm{p}=0.64$ ), ARNTL (fold change $=1.03, \mathrm{p}=0.78$ ), ARNTL2 (fold change $=-1.48, \mathrm{p}=0.004)$, PER1 (fold change $=-1.24$, $\mathrm{p}=0.002)$, PER2 (fold change $=-1.16, \mathrm{p}=0.14$ ), PER3 (fold change $=-1.06, \mathrm{p}=0.37$ ), CRY1 (fold change $=-1.32$, $\mathrm{p}=0.002$ ), CRY2 (fold change $=-1.10, \mathrm{p}=0.15$ ), CSNK1D (fold change $=-1.13, \mathrm{p}=0.004), C S N K 2 A 2$ (fold change $=-1.18, \mathrm{p}=0.04), N R 1 D 1$ (fold change $=-1.16$, $\mathrm{p}=0.01$ ), RORA (fold change $=-1.19, \mathrm{p}=0.01$ ), SIRT1 (fold change $=-1.08, \mathrm{p}=0.33$ ), and TIPIN (fold change $=-1.31$; $\mathrm{p}=0.26$ ) was not different in a statistically significant way between treated and not treated HS fibroblasts or did not reach the $\mathrm{p}<0.001$ threshold value.

Evaluation by NGS technology of clock controlled gene expression in healthy fibroblasts, untreated HS fibroblasts and HS fibroblasts 24 hours and 144 hours after treatment with idursulfase

Regarding to the clock controlled genes, in HS fibroblasts there was a statistically significant difference and dynamic change with idursulfase treatment at the time points considered of the expression of a huge number of output genes involved in the control of important cellular and tissue processes. The cellular processes driven by clock controlled genes differentially expressed with a statistical significance reaching the $\mathrm{p}<0.001$ threshold are represented by DNA transcription (AHR, ARNT, CTNNB1, FOS, FOXL2, FOXO1, HIF1A, HSF1, ID2, JUN, KEAP1, KITLG, KLF10, NFIL3, PPARA, PPARD, PPARG, RARA, RXRA, SMAD4, SP1, SREBF1, SRF, STAT1, STAT5A), post-translational modification and degradation (FBXL3, SUMO3, USP5), biosynthesis (ACSL1, AEBP1, ALAS1, APBB1, APBB1IP, APBB2, BMPR1A, CEBPB, CREBBP, FASN, GYS1, HMGCR, 
INSIG2, LPIN1, NAMPT), processing (ADA, ALDH1A1, ALDH1A3, ALDH1B1, ATF2, ATM, ATR, ATRIP, BHLHE40, BHLHE41, BNIP3, CES1, CES2, CYP7B1, E2F1, EGFR, EGR1, EIF2B3, HSP90AA1, HSPA1A, HSPA5, HSPD1, GABARAPL1, GLO1, GLUL, HK1, LDHA, LMAN1, LMAN2, MAOA, NPC1, PARP1, PCK2, PRDX2, PYGL, SGMS2, ULK1, XBP1), transport (AP2A1, AP2M1, IGFBP3, IGFBP5, LDLR, SLC22A15, SLC25A1, SLC27A1, SLC7A8, SLC9A3R2, SLC9A9), DNA damage response (ATM, ATR, ATRIP), and cell cycle control (CCNA2, CCNB1, CCND1, CDK2AP1, CDKN1A, GADD45A, $M D M 2, W E E 1)$. The tissue processes influenced by deregulated clock controlled genes are mainly represented by inflammation, hemocoagulation and fibrinolysis (ADAM17, A2M, FN1, ICAM1, IL6, ITGA5, MASP1, MGST1, NFKBIA, PDGFRA, PDGFRB, PTGS2, SERPINE1, SPP1, THBD, TFPI2, TRAF2, VEGFA).
Evaluation by qRT-PCR after Serum-Shock Induced Synchronization of changes of clock gene expression levels in healthy fibroblasts, untreated HS fibroblasts and HS fibroblasts after $\mathbf{2 4}$ hours of treatment with idursulfase After serum shock synchronization and qRT-PCR analysis, statistically significant differences were evidenced in the mRNA expression levels of ARNTL2 at $10 \mathrm{~h}$ $(\mathrm{p}=0.036)$, PER1 at $4 \mathrm{~h}(\mathrm{p}=0.019)$, PER2 at $10 \mathrm{~h}$ $(\mathrm{p}=0.041)$ and $16 \mathrm{~h}(\mathrm{p}=0.043)$, between idursulfase treated HS fibroblasts and untreated HS fibroblasts (Figure 1). Fitting of cosine curves with a 24-hour period to raw data and plotting as polarograms clock gene expression levels in control fibroblasts and fibroblasts of patients affected by HS before and after 24 hours of idursulfase treatment (Figures 2, 3 and 4) evidenced statistically significant and borderline significant rhythms of clock gene expression, and advance of phase os-

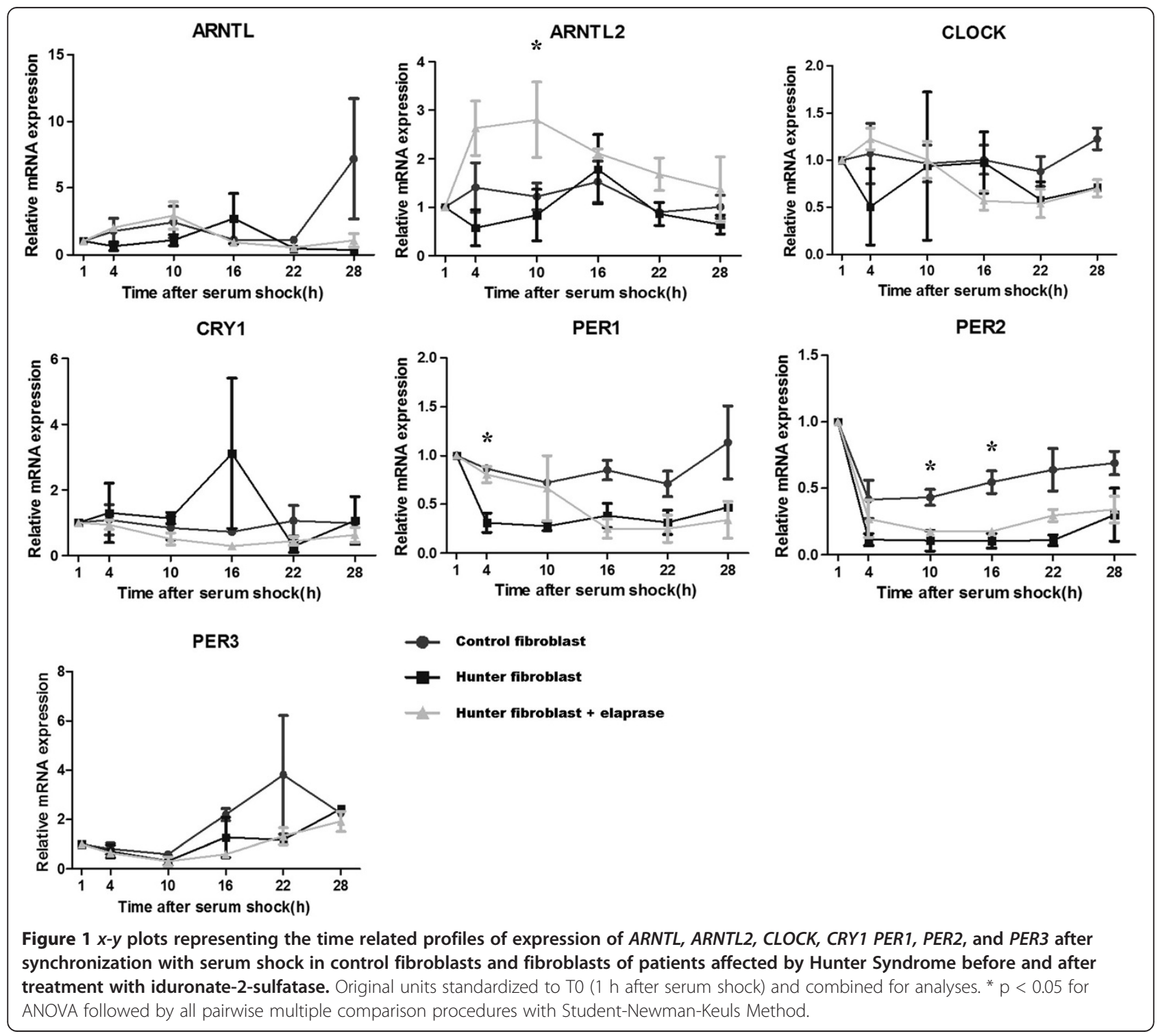


cillation after idursulfase treatment. MESOR, amplitude, acrophase and $\mathrm{p}$ values are reported in Table 1.

\section{Semantic hypergraph-based analysis of circadian gene expression}

The aim of this analysis was to determine the functional groups of genes that play any key-role in the development of HS. The analysis workflow is here preliminary sketched: (i) RNA-Sequencing: Detection of core clock gene and clock controlled gene expression profiles; (ii) Descriptive analysis and feature selection: Selection of the most varying genes by the ensemble of principal component analysis and linear discriminant analysis; (iii) Qualitative hypergraph building: Inference of weighted and signed hypergraphs; (iv) Quantitative undirected graph construction: Mathematical agglomeration of weights over the edges; (v) Weighted topology indices calculation: Computation of several weighted topology indices for each node and normalization of individual fold changes by the most discriminant index; (vi) Determination of the strongest connected components: Hierarchical clustering and matching with critical biological functions $[35,36]$.

\section{Descriptive analysis and features selection}

We have preliminarily assessed the expression variation of clock genes and clock-controlled genes, through five different states: HS (H) vs. Control (C), Treatment at time 1 (T1) vs. C, Treatment at time 2 (T2) vs. $\mathrm{C}$, and $\mathrm{T} 1$ vs. $\mathrm{H}, \mathrm{T} 2$ vs. $\mathrm{H}$. We discarded genes that did not exhibit any relevant expression change between these states. We combine a principal component analysis to determine those genes that maximally vary through the first three components, and a linear discriminant analysis to project the genes and their expressions onto the most varying components' axes (Figures 5 and 6).

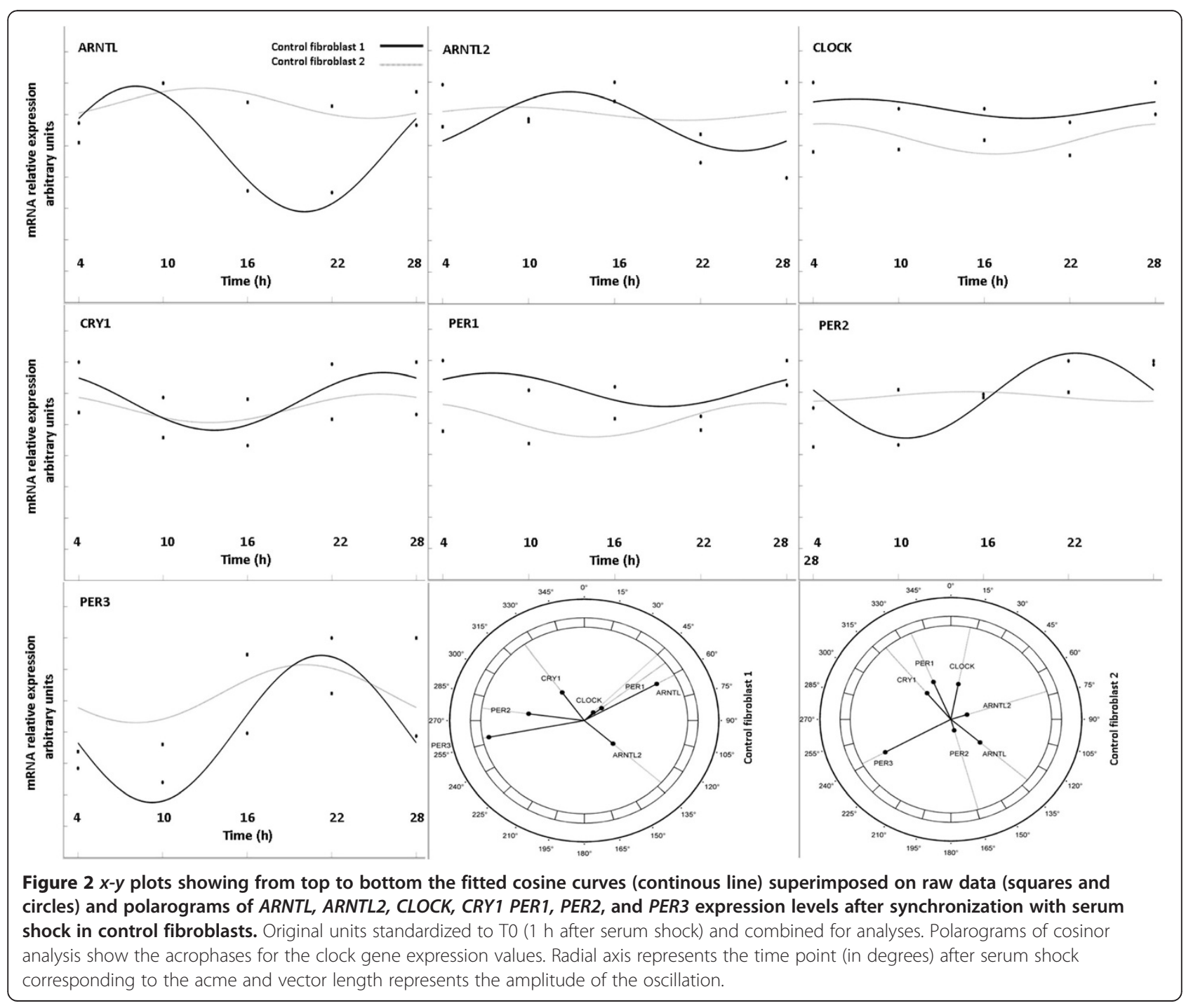




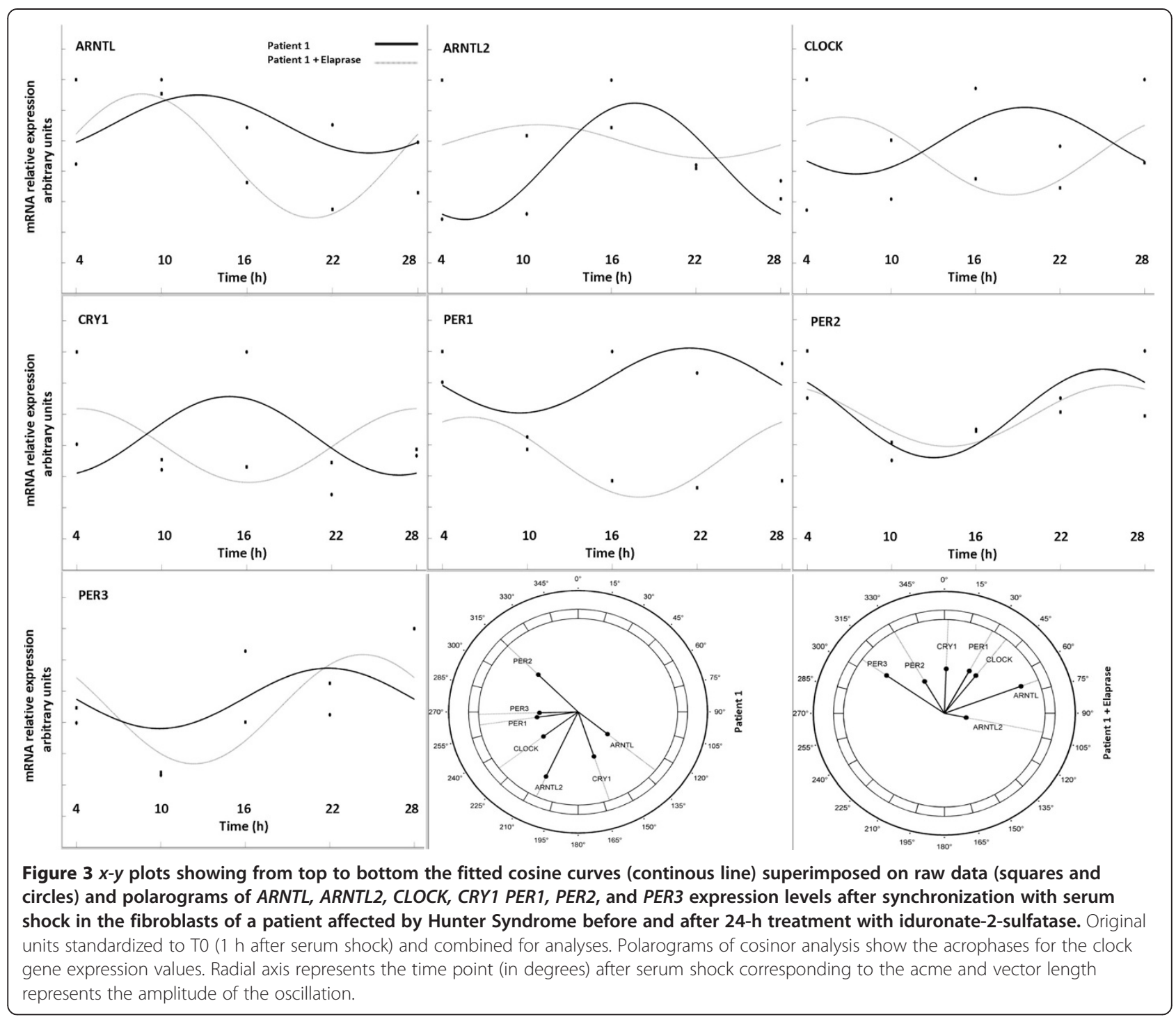

\section{Qualitative hypergraphs building}

We have assembled a hypergraph connecting genes by querying and merging a number of heterogeneous data sources: (i) Interpro and PFAM (protein domains), (ii) Gene Expression Omnibus (Co-localization and co-expression), (iii) BIOGRID and IREF (genetic interactions), (iv) PathwayCommons, IMID, NCI_NATURE, REACTOME, KEGG and BIOCARTA (pathways), (v) BIOGRID, BIND, HPRD, INTACT, MINT, MPPI and OPHID (physical interactions) and (VI) curated literature (predicted interactions). Two genes were connected by an edge, whenever at least an interaction evidence of any of the above mentioned interaction categories was found. Several pair of genes resulted to be connected by more than one edge. We built a weighted and signed hypergraph with weights over the edges (carrying the reliability of the corresponding interactions) and weights over the nodes (carrying the fold change expression of the corresponding genes) [37-39].

\section{Quantitative undirected graph}

We deterministically inferred an undirectedm graph from our hypergraph, by applying an injective function to the sets of weights over the edges connecting any two pairs of genes. This simple agglomerative weighting function takes the weights of the edges connecting any two nodes in input, and gives a unique value in output. Constitutively, it gives more and more importance to the pairs that are connected by multiple edges.

$$
W_{A B}=\frac{e^{n}}{n} \sum_{i=1}^{n} W_{A B_{i}}
$$

where $n$ is the number of edges connecting any two nodes $A$ and $B$, and $i$ refers to the $i$ th edge.

Thus, we obtain a new graph that contains the same set of nodes, and individual edges connecting any two nodes, with the newly calculated weights over them (Figure 7). 


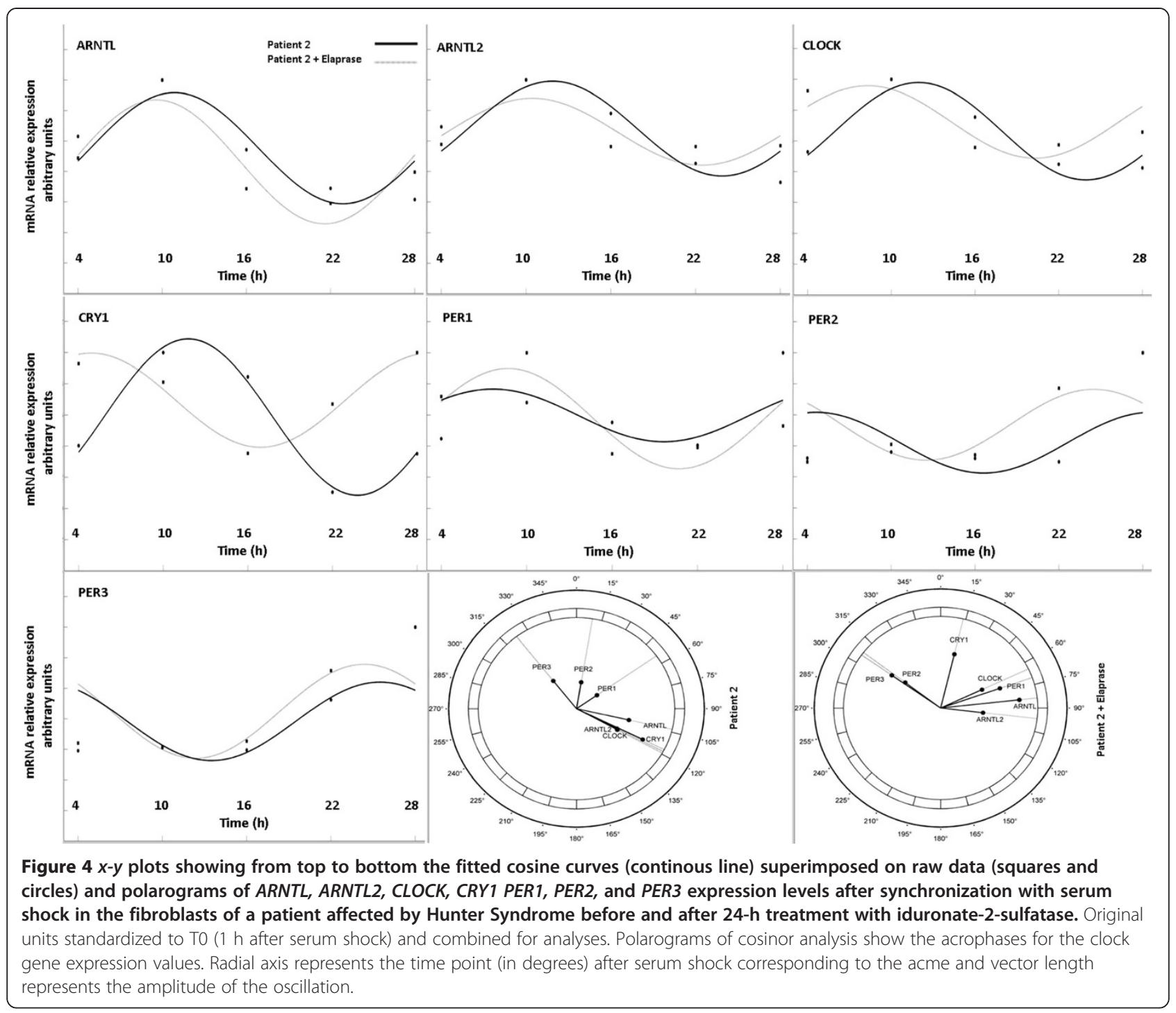

\section{Weighted topology indices calculation}

We calculated the closeness topology index for each gene. We recall that the un-weighted formulation of closeness between any two nodes of a graph measures the length of their shortest paths. The concept of closeness originates from the inverse definition of farness, namely as the inverse of the sum of the distance from a node to all other nodes. Thus, the more important a node is, the lower is its total distance to all other nodes. Closeness can be regarded as a measure of how fast it will take to spread information from a node to all other nodes sequentially. Contrarily, the weighted formulation of closeness takes into account paths whose lengths are not the sum of the minimum number of hops from a node to all other nodes, but the sum of the inverse weights over the edges of the shortest paths from a node to all other nodes. This formulation gives importance to the reliability of a connection, when determining the essentiality of each node, thereby discriminating between reliable and not-reliable interaction paths.

We have subjected the top 26 closest genes to other well-known topological indices (i.e., degree, betweenness, clustering coefficient and topological importance) and found that 5 (i.e., AHR, HIF1A, CRY1, ITGA5 and $E I F 2 B 3$, see the plot below) were highly ranked by 4 out of 5 indices (Table 2 and Figure 8).

\section{Strongly connected components determination}

After having scaled the individual fold changes with the closeness values of each gene, we have finally determined the collaborative actions of such genes by extracting the most cohesive clusters out of their interaction network. We performed a hierarchical clustering on the expression profiles of clock and clock controlled genes, by considering the Squared Euclidean distance as metric. We have subjected the found clusters to functional enrichment analysis against 
Table 1 Parameters calculated by Cosinor analysis (fitting a cosine curve with a 24-hour period to raw data) of clock gene expression levels after serum-shock induced synchronization in normal fibroblasts and fibroblasts of patients affected by Hunter syndrome before and after 24 hours of treatment with idursulfase

\begin{tabular}{|c|c|c|c|c|c|c|c|c|c|}
\hline \multicolumn{5}{|c|}{ Fibroblast of control subject 1} & \multicolumn{5}{|c|}{ Fibroblast of control subject 2} \\
\hline & MESOR & Amplitude & Acrophase & $\mathbf{P}$ & & MESOR & Amplitude & Acrophase & $\mathbf{P}$ \\
\hline ARNTL & 0.578 & 0.401 & $60^{\circ} 42^{\prime}$ & 0.048 & ARNTL & 0.872 & 0.095 & $130^{\circ} 30^{\prime}$ & 0.747 \\
\hline ARNTL2 & 0.753 & 0.186 & $131^{\circ} 58^{\prime}$ & 0.734 & ARNTL2 & 0.802 & 0.041 & $72^{\circ} 33^{\prime}$ & 0.948 \\
\hline CLOCK & 0.834 & 0.061 & $45^{\circ} 00^{\prime}$ & 0.749 & CLOCK & 0.642 & 0.096 & $11^{\circ} 11^{\prime}$ & 0.827 \\
\hline PER1 & 0.813 & 0.106 & $51^{\circ} 40^{\prime}$ & 0.592 & PER1 & 0.621 & 0.108 & $336^{\circ} 40^{\prime}$ & 0.818 \\
\hline PER2 & 0.777 & 0.271 & $277^{\circ} 45^{\prime}$ & 0.234 & PER2 & 0.772 & 0.030 & $164^{\circ} 21^{\prime}$ & 0.983 \\
\hline PER3 & 0.420 & 0.469 & $258^{\circ} 57^{\prime}$ & 0.136 & PER3 & 0.645 & 0.185 & $241^{\circ} 35^{\prime}$ & 0.825 \\
\hline CRY1 & 0.747 & 0.184 & $324^{\circ} 45^{\prime}$ & 0.577 & CRY1 & 0.704 & 0.091 & $319^{\circ} 46^{\prime}$ & 0.842 \\
\hline \multicolumn{5}{|c|}{ Fibroblast of Hunter syndrome patient 1 not treated } & \multicolumn{5}{|c|}{ Fibroblast of Hunter syndrome patient 1 treated with idursulfase } \\
\hline & MESOR & Amplitude & Acrophase & $\mathbf{P}$ & & MESOR & Amplitude & Acrophase & $\mathbf{P}$ \\
\hline ARNTL & 0.709 & 0.190 & $139^{\circ} 04^{\prime}$ & 0.493 & ARNTL & 0.499 & 0.406 & $69^{\circ} 11^{\prime}$ & 0.444 \\
\hline ARNTL2 & 0.466 & 0.383 & $204^{\circ} 48^{\prime}$ & 0.280 & ARNTL2 & 0.597 & 0.110 & $101^{\circ} 49^{\prime}$ & 0.928 \\
\hline CLOCK & 0.600 & 0.218 & $232^{\circ} 42^{\prime}$ & 0.825 & CLOCK & 0.500 & 0.255 & $37^{\circ} 52^{\prime}$ & 0.492 \\
\hline PER1 & 0.813 & 0.207 & $261^{\circ} 52^{\prime}$ & 0.516 & PER1 & 0.321 & 0.257 & $28^{\circ} 38^{\prime}$ & 0.677 \\
\hline PER2 & 0.600 & 0.282 & $315^{\circ} 00^{\prime}$ & 0.294 & PER2 & 0.585 & 0.196 & $330^{\circ} 15^{\prime}$ & 0.509 \\
\hline PER3 & 0.553 & 0.193 & $268^{\circ} 32^{\prime}$ & 0.867 & PER3 & 0.484 & 0.350 & $305^{\circ} 17^{\prime}$ & 0.390 \\
\hline CRY1 & 0.461 & 0.253 & $161^{\circ} 40^{\prime}$ & 0.643 & CRY1 & 0.399 & 0.237 & $2^{\circ} 15^{\prime}$ & 0.593 \\
\hline \multicolumn{5}{|c|}{ Fibroblast of Hunter syndrome patient 2 not treated } & \multicolumn{5}{|c|}{ Fibroblast of Hunter syndrome patient 2 treated with idursulfase } \\
\hline & MESOR & Amplitude & Acrophase & $\mathbf{P}$ & & MESOR & Amplitude & Acrophase & $\mathbf{P}$ \\
\hline ARNTL & 0.552 & 0.365 & $103^{\circ} 12^{\prime}$ & 0.298 & ARNTL & 0.462 & 0.407 & $83^{\circ} 41^{\prime}$ & 0.163 \\
\hline ARNTL2 & 0.680 & 0.310 & $114^{\circ} 09^{\prime}$ & 0.260 & ARNTL2 & 0.660 & 0.219 & $96^{\circ} 41^{\prime}$ & 0.349 \\
\hline CLOCK & 0.662 & 0.316 & $119^{\circ} 17^{\prime}$ & 0.078 & CLOCK & 0.723 & 0.235 & $64^{\circ} 40^{\prime}$ & 0.296 \\
\hline PER1 & 0.597 & 0.169 & $54^{\circ} 28^{\prime}$ & 0.713 & PER1 & 0.576 & 0.323 & $70^{\circ} 31^{\prime}$ & 0.235 \\
\hline PER2 & 0.420 & 0.196 & $9^{\circ} 22^{\prime}$ & 0.708 & PER2 & 0.535 & 0.229 & $307^{\circ} 31^{\prime}$ & 0.682 \\
\hline PER3 & 0.383 & 0.257 & $322^{\circ} 27^{\prime}$ & 0.664 & PER3 & 0.449 & 0.308 & $305^{\circ} 32^{\prime}$ & 0.572 \\
\hline CRY1 & 0.585 & 0.502 & $116^{\circ} 45^{\prime}$ & 0.009 & CRY1 & 0.694 & 0.302 & $13^{\circ} 30^{\prime}$ & 0.039 \\
\hline
\end{tabular}

Cosinor, least-squares fit of single component cosine to all data. MESOR, rhythm-adjusted overall $24 \mathrm{~h}$ mean; Amplitude, peak-trough range of cosine model ; Acrophase, peak of cosine in degrees.

the GO FAT category, and determined five clusters significantly associated to at least a biological process or pathway (Figure 9).

Cluster 1, which is made of CDK1, PER2, CCNA2, JUN, PER1, TIMELESS, CCNB1, CSNK2B, EIF2B3, NR1D1, ARNTL2, HSP90AA1, CSNK1D, E2F1, BHLHE40, CEBPB, TIPIN, ELAVL1, ATRIP, POLA1, MDM2, POLD1, HSPD1, HK1, LDHA, TRAF2, HSPA5, TBP, PPP5C, ALDH1A3, CCRN4L, CDC7, SUMO3, AHCY, POR, GNB2L1, ESRRA, ATP6V1D, USP5, $D D X 11, N R F 1, F O X L 2$, is strongly associated with several cellular processes: cell cycle (GO:0022402, p-value = 1.46E-02; GO:0000278, p-value $=2.40 \mathrm{E}-03$; etc.), DNA damage response activities (GO:0000077, p-value = 1.055E-3; GO:0007050, p-value $=4.634 \mathrm{E}-3$, etc.) and pathways, such as cell cycle (WikiPathways, WP179, p-value $=2.443 \mathrm{E}-4)$, and hypoxia-inducible factor in the cardiovascular system (BIOCARTA, p-value = 2.041E-2).

Cluster 2, which is made of $A R N T L, R X R A, C R E B B P$, ITGA5, SERPINE1, CCND1, CSNK1E, BHLHE41, CDKN1A, FN1, PKM2, PTGS2, DBP, PPARD, HSF1, THBD, IGFBP3, HSPA1A, AP2M1, TUBB, FASN, P4HA2, ALAS1, ALDH1B1, CDK2AP1, GYS1, NOTCH1, $A D A, S L C 7 A 8, S C G 5$, is associated to the inflammatory response (GO:0006954, p-value $=3.043 \mathrm{E}-2$ ), response to lipid (GO:0033993, $\mathrm{p}$-value $=1.346 \mathrm{E}-3$ ), liver development (GO:0001889, 1.025E-3) and cell motility (GO:0048870, p-value $=3.889 \mathrm{E}-3 ;$ GO:0016477, $\mathrm{p}$-value $=$ 1.823E-3).

Cluster 3, which is made of WEE1, FOS, EGR1, PDGFRB, FOXO1, PPARG, IL6, NFYB, A2M, PDGFRA, PTGDS, ICAM1, IGFBP5, NFIL3, AEBP1, LGALS9, is involved in the response to cold (GO:0009409, p-value = 


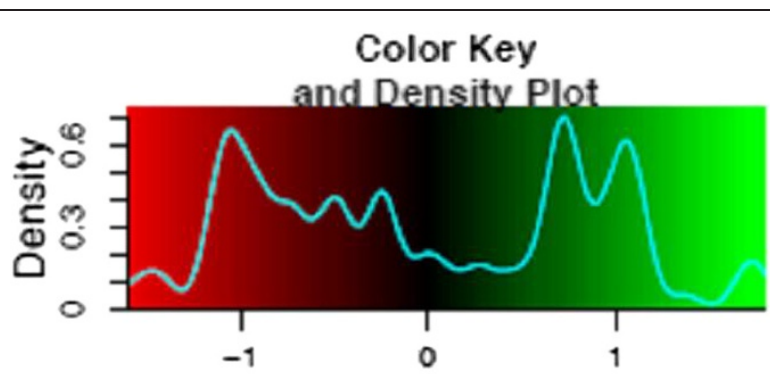

Row Z-Score

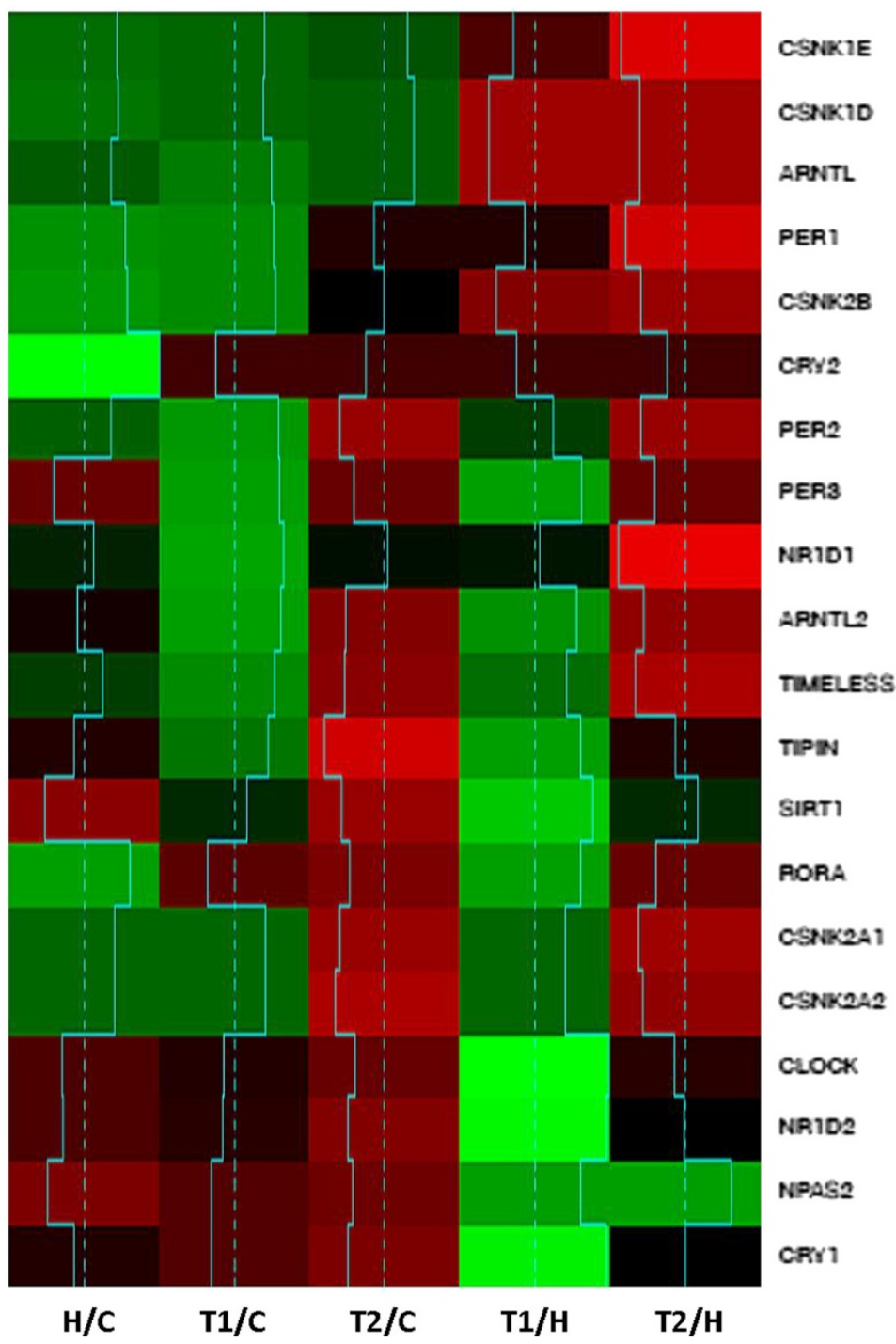

Figure 5 Heat map of the core clock gene expression fold changes between untreated patients and control cases $(\mathrm{H} / \mathrm{C})$, patients 24 or 144 hours after treatment and control cases (T1/C and T2/C), treated and untreated patients (T1/H and T2/H). Cyan segments and a density plot quantify the magnitude of intra class and global FCs, respectively.

3.126E-5) and glucose homeostasis (GO:0042593, p-value $=5.443 \mathrm{E}-3$ ).

Cluster 4, which is made of CLOCK, ARNT, PER3, EIF2B5, NPAS2, CSNK2A1, CSNK2A2, GSK3B, ATR, HDAC3, SIRT1, EIF2B2, PLAT, PARP1, HSF2, MYC,
NFYA, RORA, CHEK2, ATM, NONO, KLF10, RBX1, TPMT, KITLG, TTC1, SEC61G, SEC61A1, GCLC, SLC29A1, RCC1, SLC9A8, APBB2, SRP9, CHMP1B, ENOX2, SLC9A9, ITFG2, WDR5, AACS, cooperate with genes in cluster 1 to negatively regulate cell cycle 
Figure 6 Heat map of the clock-controlled gene expression fold changes between untreated patients and control cases $(\mathrm{H} / \mathrm{C})$, patients 24 or 144 hours after treatment and control cases (T1/ $\mathrm{C}$ and $\mathrm{T} 2 / \mathrm{C})$, treated and untreated patients ( $\mathrm{T} 1 / \mathrm{H}$ and $\mathrm{T} 2 / \mathrm{H})$. Cyan segments and a density plot quantify the magnitude of intra class and global FCs, respectively.

(GO:0007050, p-value $=3.094 \mathrm{E}-3)$, to the response to decreased oxygen levels (GO:0036293, p-value = 3.128E-2) and to participate to the P53 signaling pathway (Pathway Ontology, PW:0000718, p-value = $1.466 \mathrm{E}-2)$.

Cluster 5, which is made of $A H R, H I F 1 A, C R Y 1, R B 1$, STAT1, NFKBIA, STAT5A, PRKCA, FBXL3, NR1D2, NFE2L2, HES1, ACSL1, CXCL12, NNMT, NAMPT, EGFR, FMR1, NPC1, PYGL, NACA, LDLR, GLUL, GLO1, MGST1, BMPR1A, plays an important role in the positive regulation of epithelial cell proliferation (GO:0050678, p-value $=8.024 \mathrm{E}-7)$, response to lipid (GO:0033993, p-value $=3.898 \mathrm{E}-4 ;$ GO:0071396, $\mathrm{p}$-value $=$ 3.709E-3), tissue morphogenesis (GO:0048729, $\mathrm{p}$-value $=$ 7.487E-4) and takes part in the adipogenesis pathway (WikiPathways, WP236, p-value $=8.700 \mathrm{E}-4$ ).

\section{Discussion}

The molecular oscillator ticking in every cell regulates the customary sequence of intracellular activities, allowing the coordination of key pathways and the compartmentalization in the temporal dimension of poorly-compatible biochemical processes [40]. Altered functioning of the clock gene machinery may determine loss of time-of-day specific transcription of clock genes and clock controlled genes, causing severe deregulation of cellular homeostasis, cell dysfunction and biochemical and structural derangements that may lead to cell death and tissue dysfunction [41].

The aim of our study was to evaluate the functioning of the clock gene machinery in HS, and to address this issue we analyzed and compared mRNA expression levels of the core clock genes CLOCK, NPAS2, ARNTL1, ARNTL2, PER1, PER2, PER3, CRY1, CRY2, CSNK1D, CSNK1E, CSNK2A1, CSNK2A2,CSNK2B, NR1D1, NR1D2, RORA, SIRT1, TIMELESS, TIPIN, and a set of clock controlled genes in normal human fibroblasts and fibroblasts derived from subjects affected by Mucopolysaccharidosis type II. We also evaluated in vitro the effects of the treatment with idursulfase on circadian gene expression at different time points.

Analyzing data obtained from NGS we observed altered mRNA levels of some of the clock genes and clock controlled genes and a variable response to idursulfase treatment.

In HS fibroblasts CLOCK and NPAS2 showed lower expression levels. CLOCK and its paralog NPAS2 encode 


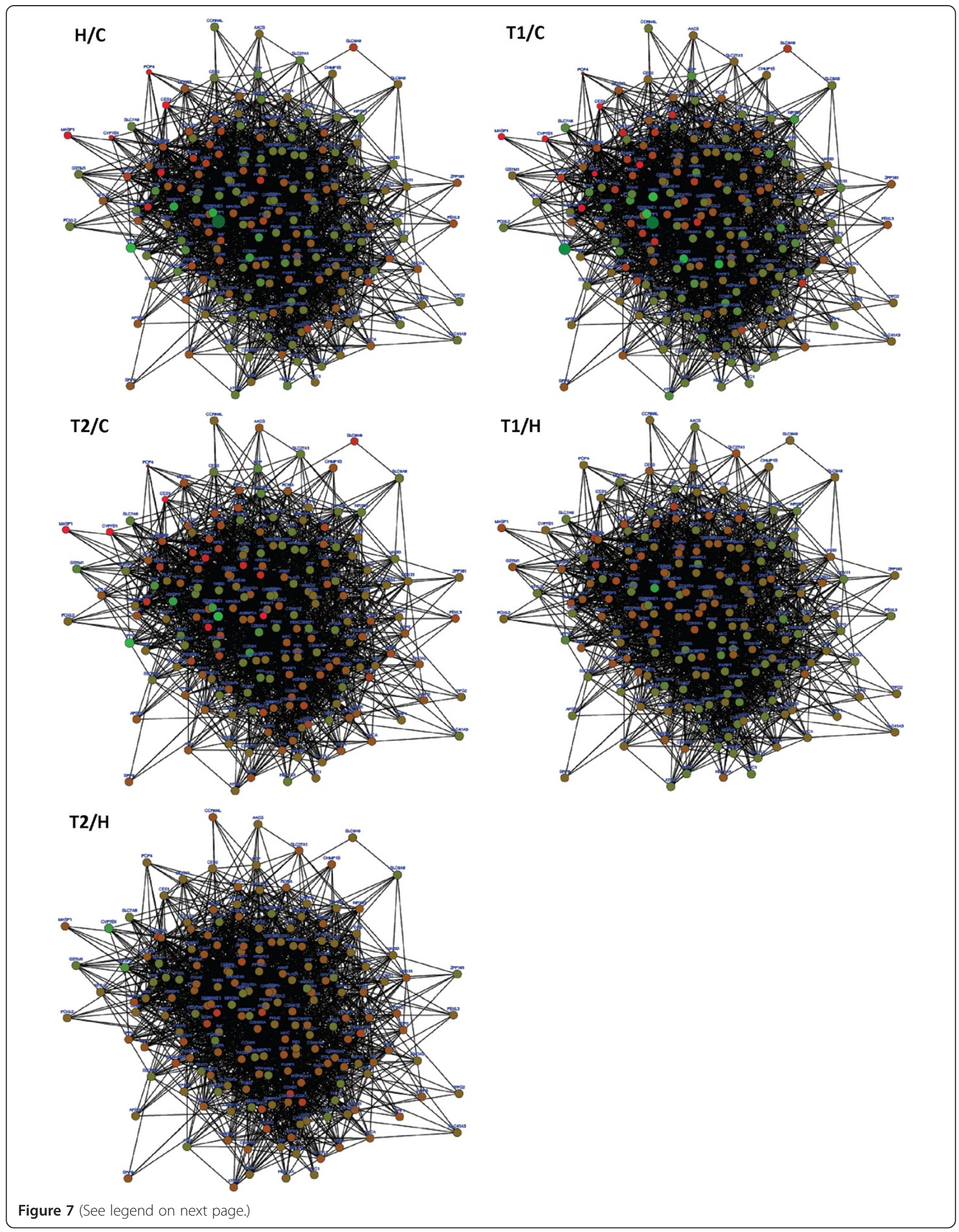


(See figure on previous page.)

Figure 7 Undirected and weighted interaction network between core clock genes and clock controlled genes in five different states: Hunter disease (H) vs. Control (C) (H/C), Treatment at time 1 (T1) vs. C (T1/C), Treatment at time 2 (T2) vs. C (T2/C) and T1 vs. H (T1/H), T2 vs. $\mathbf{H}(\mathbf{T} 2 / \mathbf{H})$. Nodes colors range from red (negative FC) to green (positive FC). Diameter of nodes is proportional to the magnitude of the FC. Thickness of edges varies with the reliability of the interaction. Overall, the network exhibits the following global topological properties: clustering coefficient $=0.293$, connected components $=1$, diameter $=4$, radius $=2$, centralization $=0.259$, shortest paths $=35910$ ( $100 \%$, characteristic path length $=2.002$, average number of neighbors $=25.484$, density $=0.135$ and heterogeneity $=0.498$. transcription factors belonging to the basic helix-loophelix/Per-Arnt-Simpleminded (bHLH-PAS) domain family, and represent key elements in the positive limb of the transcriptional-translational feed-back loop that drives circadian rhythmicity of the oscillatory functions underlying cell homeostasis. In particular, their encoded proteins have histone acetyltransferase activity and are involved in chromatin remodeling with specificity for histones $\mathrm{H} 3 / \mathrm{H} 4$ [42]. ARNTL, the heterodimerization partner of CLOCK and NPAS2, enhances their enzymatic function, and the decreased expression of these central components of the molecular clock could hinder the correct clock gene expression in the fibroblasts of Mucopolysaccharidosis type II patients.

A lower expression level was found in HS fibroblasts for CRY1, whereas PER1 was up-regulated. The mammalian Period and Cryptochrome genes are both E-box-regulated genes, but in peripheral tissues CRY1 mRNA expression peak is delayed by several hours with respect to that of PER1. CRY1 usually shows evening-time expression and serving as a strong repressor at morningtime elements ensures a delay in feedback repression in the molecular clock. This phase delay in CRY1 transcription is required for customary mammalian clock function [43]. The E-box (CACGTG) is crucial for daytime transcriptional activity and the delay originates from interactions between the proximal E-box and ROR response elements (RORE) present in the CRY1 promoter [44].

A higher expression level was found in HS fibroblasts for CSNK1D and CSNK1E, encoding the serine/threonine protein kinase casein kinase $(\mathrm{CK})$ I $\delta$ and $\varepsilon$ respectively, which are key regulators of metazoan circadian rhythmicity. CKI binds to and phosphorylates the Period proteins, wich in turn interact with a variety of circadian regulators, suggesting the possibility that CKI may interact with and phosphorylate additional clock components as well [45]. Cryptochrome proteins are phosphorylated by CKI only when both proteins are bound to mammalian Period proteins [12]. ARNTL is also a substrate for CKI in vitro, and CKI activity positively regulates ARNTL-dependent transcription from circadian promoters in reporter assays [12]. CKI phosphorylates multiple circadian substrates and may exert its effects on circadian rhythm in part by a direct effect on ARNTLdependent transcription $[12,45]$. The up-regulation of these protein kinases found in HS fibroblasts could play a crucial role in the derangement of the clock gene machinery and the downstream controlled pathways, but on the other hand CKs could represent important molecular targets for new therapeutic approaches.

In HS fibroblasts we found higher expression of NR1D1, and lower expression of NR1D2. NR1D1 and NR1D2, activated by CLOCK/NPAS2:ARNTL/ARNTL2 heterodimers, code respectively for the orfan nuclear receptors REV ERB $\alpha$ and REV ERB $\beta$, which realize a supplementary loop amplifying and stabilizing the oscillation of the molecular clockwork. REV-ERB $\alpha$ and REV-ERB $\beta$ act as negative transcriptional regulators by binding RORE in gene promoters, preventing the binding of the positive transcriptional regulator $\mathrm{ROR} \alpha$, and negatively regulating the expression of $A R N T L, C L O C K$, and CRY1 $[46,47]$. In addition, REV-ERB $\alpha$ is directly involved in lipid metabolism antagonizing the opposite role of ROR $\alpha$ and inhibiting the expression of genes coding for apolipoprotein C-III, a constituent of very-low-density lipoproteins [48].

A lower expression level was found in HS fibroblasts for SIRT1, which regulates metabolic and stress responses acting in concert with the circadian rhythm machinery [49]. SIRT1 is involved in a number of cellular processes, including gene silencing at telomere and mating loci, and modulates cell survival by inhibiting apoptosis or cellular senescence induced by external challenges, including DNA damage and oxidative stress [50]. SIRT1 impinges on Ku70, peroxisome proliferator activated receptors, p53 and the forkhead box $O$ (FOXO) family of transcription factors, and is modulated by active regulator of SIRT1 (AROS), hypermethylated in cancer 1 (HIC-1), deleted in breast cancer 1 (DBC1) and E2F transcription factor 1 (E2F1) [49-51]. Interestingly, E2F1 was greatly over-expressed in HS fibroblasts, but normalized after 144 hours of IDS treatment, whereas FOXO1 was severely down regulated, and responded faintly to IDS treatment. Besides, in HS fibroblasts there was severe down-regulation with no response to IDS treatment of NAMPT, encoding the enzyme controlling the synthesis of nicotinamide adenine dinucleotide $\left(\mathrm{NAD}^{+}\right)$, a cofactor of SIRT1, linking nutrient sensing and circadian regulation [52].

After 24 hours of treatment with idursulfase in fibroblasts of patients with Mucopolysaccharidosis type II the 
Table 2 The top 26 closest genes subjected to other well-known topological indices (i.e., degree, betweenness, clustering coefficient and topological importance)

\begin{tabular}{|c|c|c|c|c|c|c|c|c|c|}
\hline Gene & Degree & Gene & Betweenness & Gene & Closeness & Gene & Clustcoefficient & Gene & Top Importance \\
\hline CDK1 & 1.16518997973136 & AEBP1 & 0.0391432466904165 & AP2M1 & 24.1307228971342 & CCNB1 & 0.667477524717011 & HIF1A & 2.82727459653061 \\
\hline ARNTL & 0.62961382177992 & GABARAPL1 & 0.0337159695650262 & AEBP1 & 24.0044419343927 & WEE1 & 0.327773492337581 & TP53 & 2.2936294377538 \\
\hline WEE1 & 0.551381703183312 & AP2M1 & 0.0322382020495228 & ALAS1 & 23.9091457589775 & EIF2B2 & 0.144963120091208 & JUN & 2.27910640635946 \\
\hline CLOCK & 0.541276442699399 & CDK2AP1 & 0.0315960768790957 & MADD & 23.610217143035 & NFE2L2 & 0.127090889959061 & AHR & 2.086410666558505 \\
\hline ARNT & 0.510341236219266 & CRY1 & 0.0260192637551128 & SCG5 & 23.5584599878639 & PER3 & 0.091787769071256 & MAPK3 & 1.99897079303812 \\
\hline PER2 & 0.470238863055953 & HK1 & 0.020820688745217 & CDK2AP1 & 23.5469067680977 & DBP & 0.0907867845842636 & ARNTL & 1.95211068089632 \\
\hline CCNA2 & 0.439051786404152 & PCBD1 & 0.0200202313409861 & PKM2 & 23.4572802663874 & CRY1 & 0.082970740931625 & BHLHE40 & 1.94713716381873 \\
\hline AHR & 0.416056158700292 & ALAS1 & 0.0183753353564674 & CYP7B1 & 23.4449074706404 & CRY2 & 0.0756826260846772 & PPARG & 1.87394548486246 \\
\hline PER3 & 0.394401965276283 & PKM2 & 0.0179531160663236 & GABARAPL1 & 23.3945147175824 & PER2 & 0.071064631749534 & CEBPB & 1.84665878053937 \\
\hline JUN & 0.390762193059339 & ITGA5 & 0.0178387650085763 & HK1 & 23.1739586467746 & ADA & 0.0690243684292723 & FOS & 1.84102240012328 \\
\hline CRY2 & 0.389512630608661 & HIF1A & 0.017777191362097 & SLC27A1 & 22.8176492281657 & NACA & 0.0657467403759448 & NFIL3 & 1.7612499926888 \\
\hline PER1 & 0.385914004666131 & MADD & 0.0159827593789858 & EIF2B3 & 22.5884323963263 & EIF2B3 & 0.0615477588018198 & $\mathrm{AHCY}$ & 1.75501225622585 \\
\hline HIF1A & 0.373867980001836 & PDGFRB & 0.0157804459691252 & CSNK1E & 22.5498678271054 & NPAS2 & 0.0601731548069088 & ITGA5 & 1.73523600034203 \\
\hline FOS & 0.366660049188066 & EIF2B3 & 0.0151383207986982 & CRY1 & 22.5300456552822 & CCNA2 & 0.0547892603398778 & GSK3B & 1.73339775429975 \\
\hline CRY1 & 0.343702809331051 & PRKCA & 0.0145929542155957 & SERPINE1 & 22.4848488761108 & PER1 & 0.0515484999929679 & MYC & 1.72885994647542 \\
\hline TIMELESS & 0.305749308005903 & CYP7B1 & 0.0142762897479879 & AHR & 22.3586129186158 & BNIP3 & 0.0495391099313379 & EGFR & 1.71329372276415 \\
\hline RXRA & 0.262643997630735 & CEBPB & 0.0135198135198135 & LGALS9 & 22.252427091889 & HK1 & 0.0452462291589491 & CDKN1A & 1.70167462718295 \\
\hline CCNB1 & 0.249481205055106 & SCG5 & 0.013159167876149 & LDLR & 22.1424073916989 & ARNTL2 & 0.0431626137068269 & PDGFRB & 1.67570618006341 \\
\hline RARA & 0.212303842977224 & CSNK2A1 & 0.0129216695254431 & SRF & 22.1323817719809 & FBXL3 & 0.0427148551020932 & NNMT & 1.67192063943735 \\
\hline EIF2B5 & 0.211018680676354 & NR1D2 & 0.0124202841183973 & SEC61G & 22.1049070311325 & CLOCK & 0.0395097804135942 & $\mathrm{AP} 2 \mathrm{M} 1$ & 1.64526410912342 \\
\hline NPAS2 & 0.205625544420401 & HEBP1 & 0.0120684347099441 & CEBPB & 21.999792977691 & TIMELESS & 0.0393934593277985 & PARP1 & 1.63582453346807 \\
\hline CSNK2A1 & 0.195935112886188 & AHR & 0.0118221401240269 & HSF1 & 21.9210101165568 & BHLHE41 & 0.0370993928249183 & CDK1 & 1.54911430562063 \\
\hline CREBBP & 0.190951965351357 & CSNK1E & 0.0117341777719136 & ITGA5 & 21.8931454731799 & BHLHE40 & 0.0359260940771708 & VEGFA & 1.48068779917142 \\
\hline CSNK2B & 0.186506665124637 & TP53 & 0.0113911245986718 & GLUL & 21.8821482612889 & ARNTL & 0.0343347266280929 & $\mathrm{HDAC3}$ & 1.47924179392207 \\
\hline ITGA5 & 0.186467727050273 & LDLR & 0.0112151998944452 & PDGFRB & 21.6377733649355 & CSNK2A2 & 0.0294553443471268 & AEBP1 & 1.46811686042305 \\
\hline EIF2B3 & 0.171980851648026 & IGFBP5 & 0.0108985354268373 & HIF1A & 21.6135335177089 & CCRN4L & 0.0249820497668383 & CCNA2 & 1.45373180796276 \\
\hline
\end{tabular}




\section{TOPOLOGY HITS}

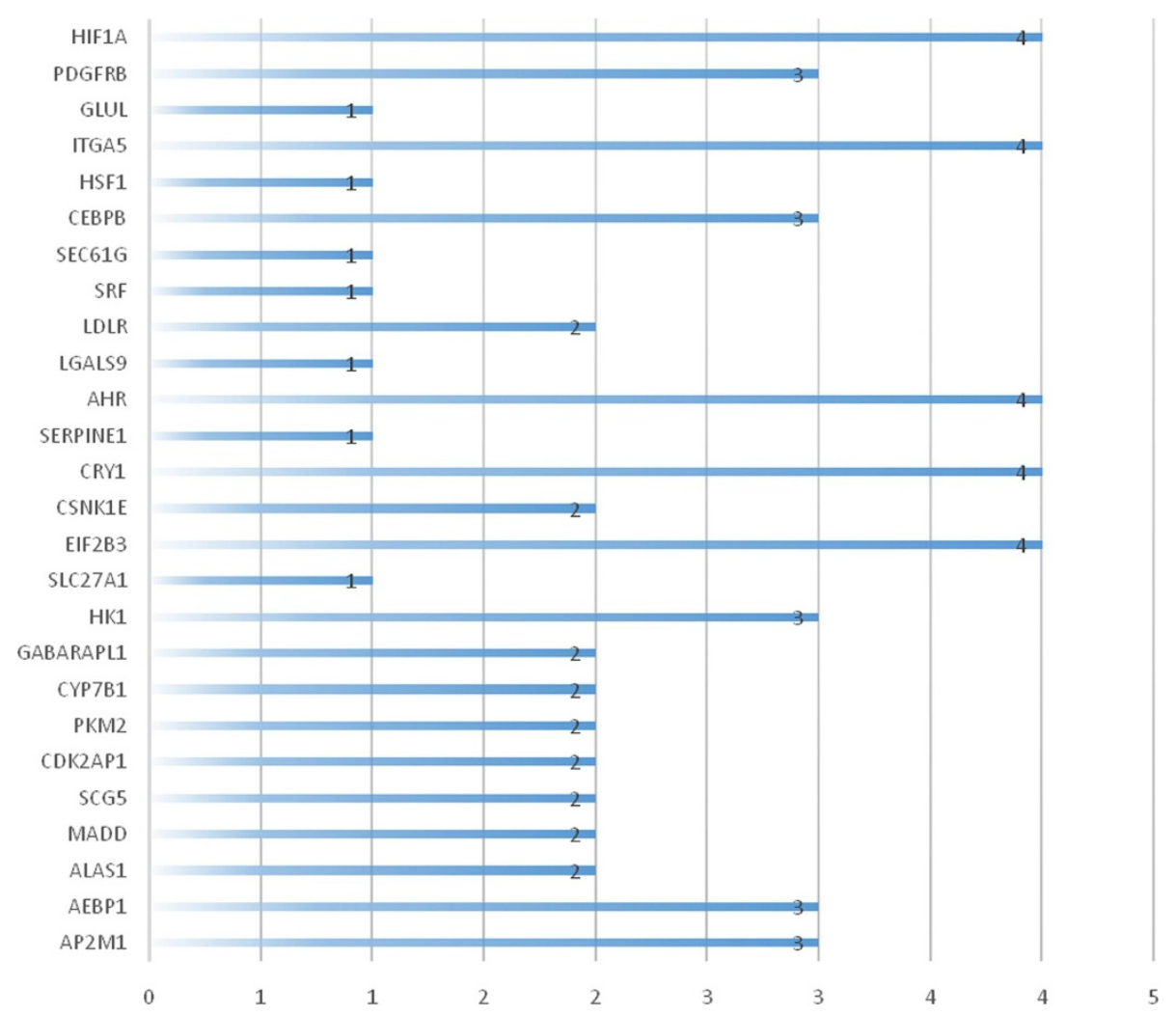

Figure 8 Genes with the highest topological scores. AHR, HIFIA, CRY1, EIF2B3, and ITGA5 are among the top 26 most ranked genes by 4 out of 5 indices.

expression evaluated by NGS of the genes CLOCK, ARNTL2, NR1D1, NR1D2, and TIMELESS showed higher expression levels compared to untreated HS fibroblasts. This effect faded completely after 144 hours, and at this time point CSNK1E, CSNK2A1, CSNK2B, NR1D2, and TIMELESS genes showed decreasing expression levels. Accordingly, the evaluation by qRT-PCR of clock gene expression upon synchronization through serum shock of normal fibroblasts and fibroblasts of patients affected by Hunter syndrome before and after 24 hours of idursulfase treatment evidenced a statistically significant effect on the expression levels of ARNTL2, PER1 and PER2, but only at the earlier time points examined, with advance of the phase of oscillation of gene expression.

Regarding to the clock controlled genes, in Hunter syndrome fibroblasts there was alteration and dynamic change with idursulfase treatment at the time point considered of

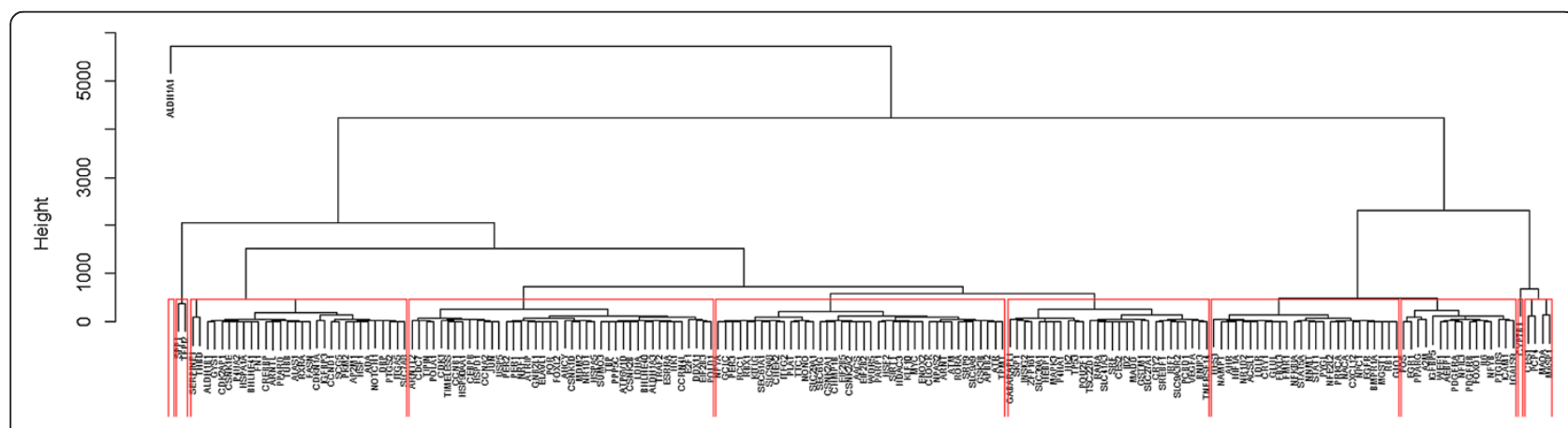

Figure 9 Hierarchical clustering of the weighted interaction networks. Genes are clustered according to the proximity of their expression profiles, evaluated by an Euclidean distance metrics. 
the expression of a huge number of output genes involved in the control of important cellular and tissue processes. An example is represented by SERPINE1, which showed higher expression levels in HS fibroblasts when compared to healthy fibroblasts, increased after 24 hours of idursulfase treatment, and decreased after 144 hours. SERPINE1 codes for the plasminogen activator inhibitor (PAI)-1, the major component of inhibitors of fibrinolysis, whose activity shows a clear circadian oscillation peaking in the early morning. CLOCK:ARNTL and CLOCK:ARNTL2 heterodimers activate the SERPINE1 promoter, driving the circadian variation in circulating PAI-1, and CLOCK: ARNTL2 heterodimer, binding two E-box enhancers in the promoter, shows double capability to activate PAI-1 expression [53].

The timing of processes that underlay cell function and the customary sequence of activation of key pathways depend on the correct ticking of the biological clock. Accordingly, the altered expression of clock controlled genes found in HS fibroblasts could hinder normal output of the clock gene machinery (BHLHE40, BHLHE41, NFIL3), and cellular activities, such as DNA transcription (CTNNB1, FOS, FOXL2, FOXO1, HIF1A, HSF1, ID2, JUN, KEAP1, KITLG, KLF10, PPARA, PPARD, PPARG, RARA, RXRA, SMAD4, SP1, SREBF1, SRF, STAT1, STAT5A), posttranslational modification and degradation (FBXL3, SUMO3, USP5), lipid and glucose metabolism and biosynthetic pathways (ACSL1, AEBP1, ALAS1, APBB1, APBB1IP, APBB2, BMPR1A, CREBBP, FASN, GYS1, HMGCR, INSIG2, LPIN1, NAMPT), molecular processing (ADA, ALDH1A1, ALDH1A3, ALDH1B1, ATF2, CES1, CES2, CYP7B1, E2F1, EGFR, EGR1, EIF2B3, HSP90AA1, HSPA1A, HSPA5, HSPD1, GLO1, GLUL, HK1, LDHA, LMAN1, LMAN2, MAOA, NPC1, PARP1, PCK2, PRDX2, PYGL, SGMS2), molecular transport (AP2A1, AP2M1, IGFBP3, IGFBP5, LDLR, SLC22A15, SLC25A1, SLC27A1, SLC7A8, SLC9A3R2, SLC9A9), DNA damage response (ATM, ATR, ATRIP), endoplasmic reticulum stress and unfolded protein response $(X B P 1)$, xenobiotic response $(A H R$, $A R N T$ ), autophagy (BNIP3, CEBPB, GABARAPL1, ULK1), cell cycle control (CCNA2, CCNB1, CCND1, CDK2AP1, CDKN1A, GADD45A, MDM2, WEE1), and tissue processes, such as inflammation, hemocoagulation and fibrinolysis (ADAM17, A2M, FN1, ICAM1, IL6, ITGA5, MASP1, MGST1, NFKBIA, PDGFRA, PDGFRB, PTGS2, SERPINE1, SPP1, TFPI2, THBD, TRAF2,VEGFA) [27-30,54].

The semantic hypergraph-based analysis of circadian gene expression brought out five gene clusters significantly associated to at least one biological process or pathway (cell cycle, DNA damage response, inflammation, liver development, cell motility, glucose homeostasis, response to cold and to decreased oxygen levels, the P53 signaling pathway, the positive regulation of epithelial cell proliferation, tissue morphogenesis, response to lipid, and the adipogenesis pathway). Besides, five genes, AHR, HIF1A, CRY1, ITGA5, and $E I F 2 B 3$, were highlighted as top ranked by all the five considered topological indices and characterized by multifaceted centrality nature in the network analysis of the circadian transcriptome. The results suggest an interesting connection between circadian and hypoxic pathways and the toxicological signal mediator, the Aryl Hydrocarbon Receptor (AHR). Upon xenobiotic binding, AHR transcriptionally activates xenobiotic metabolizing enzymes and regulates molecules involved in the signaling of nuclear factor-erythroid 2-related factor-2 (Nrf2), p53 (TRP53), retinoblastoma (RB1), and NF- $\mathrm{BB}$, influencing cellular responses to oxidative stress and inflammation. Through activation of these signaling pathways, regulation of cell cycle, and interactions with hypoxia-inducible factors (HIFs), AHR takes part in endogenous developmental functions during hematopoietic stem-cell maintenance and differentiation [55]. Intriguingly, the deficit of CRY proteins causes constitutive NF- $\mathrm{KB}$ and protein kinase A signaling activation, leading to unrelenting increase of proinflammatory cytokines, and ITGA5 encodes a receptor for fibronectin and fibrinogen, playing a role in chemotaxis, leukocyte migration, cell-cell adhesion, angiogenesis, and blood coagulation [56,57].

On the other hand, a cross-talk exists between circadian and AHR signaling pathways at genetic, epigenetic and proteomic level, and this interaction might play a role in the regulatory influences maneuvered by circadian rhythmicity on cell physiology [58]. Regarding to the interaction between hypoxic pathways and AHR complex, it has been proven that in endothelial cells AHR has a physiological function in the absence of exogenous ligands, and upon activation mediates toxicity of halogenated aromatic hydrocarbons. In addition, evidence suggests that hypoxia induces HIF dependent gene expression, significantly reducing AHR expression level and AHR-mediated expression of cytochrome P-450 phase I xenobiotic metabolizing enzyme CYP1A1 [59]. A cross-talk exists between hypoxic and circadian pathways operated by the PAS protein family members PER and CLOCK and HIF- $1 \alpha$. Interestingly, the components of AHR, circadian and hypoxic pathways are characterized by a PAS domain that serves as an interface for protein-protein interactions [60]. Moreover, cell proliferation and differentiation both in vitro and in vivo are highly influenced by oxygen concentration, and neuronal stem cell proliferation and neuronal and oligodendroglial differentiation are enhanced by a mild level of hypoxia [61]. Intriguingly, EIF2B3 encodes one of the subunits of initiation factor EIF2B, which catalyzes the exchange of eukaryotic initiation factor 2-bound guanosine-diphosphate (GDP) for guanosine-5'-triphosphate (GTP), representing an essential factor for protein synthesis, and mutations in this gene have been associated with neurodegenerative and white matter diseases [62-64]. 
Taking into account some limitations of the study, represented by the limited number of patients, suffering from a disease that is clinically heterogeneous in terms of onset, severity and progression, the dynamic variation of expression levels observed for core clock genes and clock controlled genes in the fibroblasts of patients affected by HS at different time points of treatment with idursulfase may be an indirect evidence of the key role played by the molecular clock in the regulation of the complex array of cellular functions in this mucopolysaccharidosis. A paradigm is represented by the altered expression of the clock controlled genes NPC1 and SGMS2, which are down-regulated in HS fibroblasts and increase temporarily after idursulfase treatment.

\section{Conclusion}

Biological processes show time related variations driven by genetically encoded oscillators operated by transcriptional/translational feedback loops hardwired by the clock genes and their coded circadian proteins. Data obtained in our study show that circadian gene expression is variably altered in the fibroblasts of subjects affected by HS, the treatment with idursulfase determines some modifications in the expression levels of clock genes and clock controlled genes, but these changes are temporary and fade in the course of treatment. Altered functioning of the clock gene machinery in HS may determine severe deregulation of cellular homeostasis, cell dysfunction and biochemical and structural derangements that may lead to cell death. These alterations are related to the key role played by the molecular clockwork in the control of downstream gene expression regulating a complex array of cellular functions, such as molecule biosynthesis, post-translational modification, processing, transport, conjugation, internalization and degradation, and cell processes such as cell cycle, autophagy, apoptosis and DNA damage response.The alteration of clock gene expression levels and the response to the deficient enzyme suggest a direct involvement of the molecular clock machinery in the physiopathology of cellular derangements that characterize Mucopolysaccharidosis type II, opening the way to possible new therapeutic strategies.

\section{Additional file}

Additional file 1: Table S1. Expression levels of core clock genes and clock controlled genes evaluated by whole transcriptome analysis performed through Next Generation Sequencing technology in normal human fibroblasts (Control) and fibroblasts of mucopolysaccharidosis Type II patients before (Hunter), 24 hours (T1) and 144 hours (T2) after idursulfase treatment.

\section{Competing interest}

The authors declare that there are no conflicts of interest with respect to the authorship and/or publication of this article.

\section{Authors' contributions}

GM and M Scarpa conceived the study, participated in its design and coordination and helped to draft the manuscript; RT, FD, AZ and VP carried out cell cultures and molecular genetic studies; M Salvalaio and LR participated in experimental plan design and whole transcriptome data production/analysis, MV participated in the study coordination and helped to draft the manuscript, MF, FG and TM performed bioinformatic and statistical analyses. All authors read and approved the final manuscript.

\section{Acknowledgements}

The "Cell Line and DNA Biobank from Patients affected by Genetic Diseases" (Istituto G. Gaslini, Genoa, Italy), member of the Telethon Network of Genetic Biobanks (project no. GTB12001), provided us with HS primary fibroblasts. Healthy primary fibroblasts were kindly provided by the Department of Histology, Microbiology and Medical Biotechnology, University of Padova Italy. The authors thank Prof. Giorgio Valle, Dr. Alessandro Albiero, Dr. Riccardo Schiavon of the Centre of Biotechnology of the University of Padova - Italy (CRIBI) for collaboration on RNA sequencing and for performing data alignment. The study was supported by the " $5 \times 1000$ " voluntary contribution and by a grant from the Italian Ministry of Health through Department of Medical Sciences, Division of Gastroenterology (RC1203GA55 and RC1203GA56) and Division of Internal Medicine and Chronobiology Unit (RC1201ME04 and RC1302ME31), IRCCS Scientific Institute and Regional General Hospital "Casa Sollievo della Sofferenza", Opera di Padre Pio da Pietrelcina, San Giovanni Rotondo (FG), Italy.

\section{Author details}

'Department of Medical Sciences, Division of Internal Medicine and Chronobiology Unit, IRCCS Scientific Institute and Regional General Hospital "Casa Sollievo della Sofferenza", S.Giovanni Rotondo (FG), Italy. 'Laboratory of Diagnosis and Therapy of Lysosomal Disorders, Department of Women's and Children's Health, University of Padova, Padova, Italy. ${ }^{3}$ Bioinformatics Unit, IRCCS Scientific Institute and Regional General Hospital "Casa Sollievo della Sofferenza", S.Giovanni Rotondo (FG), Italy. ${ }^{4}$ Research Laboratory of Gastroenterology Unit, IRCCS Scientific Institute and Regional General Hospital "Casa Sollievo della Sofferenza", S.Giovanni Rotondo (FG), Italy. ${ }^{5}$ Computing Unit, IRCCS Scientific Institute and Regional General Hospital "Casa Sollievo della Sofferenza", S.Giovanni Rotondo (FG), Italy. 'Institute for Liver and Digestive Health, Division of Medicine, Royal Free Campus, University College London, London, UK. ${ }^{7}$ Centre for Rare Disorders, IRCCS Scientific Institute and Regional General Hospital "Casa Sollievo della Sofferenza", S.Giovanni Rotondo (FG), Italy.

Received: 11 June 2013 Accepted: 19 September 2013 Published: 2 October 2013

\section{References}

1. Lampe C, Bellettato CM, Karabul N, Scarpa M: Mucopolysaccharidoses and other lysosomal storage diseases. Rheum Dis Clin North Am 2013, 39:431-455

2. Scarpa M, Almássy Z, Beck M, Bodamer O, Bruce IA, De Meirleir L, Guffon N, Guillén-Navarro E, Hensman P, Jones S, Kamin W, Kampmann C, Lampe C, Lavery CA, Teles EL, Link B, Lund AM, Malm G, Pitz S, Rothera M, Stewart C, Tylki-Szymańska A, van der Ploeg A, Walker R, Zeman J, Wraith JE: Hunter Syndrome European Expert Council: Mucopolysaccharidosis type II: European recommendations for the diagnosis and multidisciplinary management of a rare disease. Orphanet J Rare Dis 2011, 6:72.

3. Lowrey PL, Takahashi JS: Genetics of the mammalian circadian system: photic entrainment, circadian pacemaker mechanisms, and posttranslational regulation. Annu Rev Genet 2000, 34:533-562.

4. Mazzoccoli G: The timing clockwork of life. J Biol Regul Homeost Agents 2011, 25:137-143.

5. Bass J: Circadian topology of metabolism. Nature 2012, 491:348-356

6. Schibler U, Sassone-Corsi P: A web of circadian pacemakers. Cell 2002, 111:919-922.

7. Reyes BA, Pendergast JS, Yamazaki S: Mammalian peripheral circadian oscillators are temperature compensated. J Biol Rhythms 2008, 23:95-98.

8. Hastings $\mathrm{MH}$, Reddy $\mathrm{AB}$, Maywood ES: A clockwork web: circadian timing in brain and periphery, in health and disease. Nat Rev Neurosci 2003, 4:649-661. 
9. Houben T, Deboer T, van Oosterhout F, Meijer JH: Correlation with behavioral activity and rest implies circadian regulation by SCN neuronal activity levels. J Biol Rhythms 2009, 24:477-487.

10. Pezuk P, Mohawk JA, Yoshikawa T, Sellix MT, Menaker M: Circadian organization is governed by extra-SCN pacemakers. J Biol Rhythms 2010, 25:432-441.

11. Nagoshi E, Saini C, Bauer C, Laroche T, Naef F, Schibler U: Circadian gene expression in individual fibroblasts: cell-autonomous and self-sustained oscillators pass time to daughter cells. Cell 2004, 119:693-705.

12. Eide EJ, Vielhaber EL, Hinz WA, Virshup DM: The circadian regulatory proteins BMAL1 and Cryptochromes are substrates of Casein Kinase I $\varepsilon$. J Biol Chem 2002, 277:17248-17254

13. Cho H, Zhao X, Hatori M, Yu RT, Barish GD, Lam MT, Chong LW, DiTacchio L, Atkins AR, Glass CK, Liddle C, Auwerx J, Downes M, Panda S, Evans RM: Regulation of circadian behaviour and metabolism by REV-ERB- $a$ and REV-ERB-ß. Nature 2012, 485:123-127

14. Mazzoccoli G, Cai Y, Liu S, Francavilla M, Giuliani F, Piepoli A, Pazienza V, Vinciguerra M, Yamamoto T, Takumi T: REV-ERBa and the clock gene machinery in mouse peripheral tissues: a possible role as a synchronizing hinge. J Biol Regul Homeost Agents 2012, 26:265-276.

15. Asher G, Schibler U: Crosstalk between components of circadian and metabolic cycles in mammals. Cell Metab 2011, 13:125-137.

16. Unsal-Kaçmaz K, Chastain PD, Qu PP, Minoo P, Cordeiro-Stone M, Sancar A Kaufmann WK: The human Tim/Tipin complex coordinates an Intra-S checkpoint response to UV that slows replication fork displacement. Mol Cell Biol 2007, 27:3131-3142.

17. Smith KD, Fu MA, Brown EJ: Tim-Tipin dysfunction creates an indispensible reliance on the ATR-Chk1 pathway for continued DNA synthesis. J Cell Biol 2009, 5:15-23.

18. Yang X, Wood PA, Hrushesky WJ: Mammalian TIMELESS is required for ATM-dependent CHK2 activation and G2/M checkpoint control. J Biol Chem 2010, 285:3030-3034.

19. Kemp MG, Akan Z, Yilmaz S, Grillo M, Smith-Roe SL, Kang TH, Cordeiro-Stone M, Kaufmann WK, Abraham RT, Sancar A, Unsal-Kaçmaz K: Tipin-replication protein A interaction mediates Chk1 phosphorylation by ATR in response to genotoxic stress. J Biol Chem 2010, 285:16562-16571.

20. Matsuo T, Yamaguchi S, Mitsui S, Emi A, Shimoda F, Okamura H: Control mechanism of the circadian clock for timing of cell division in vivo. Science 2003, 302:255-259.

21. Filipski E, King VM, Etienne MC, Li XM, Claustrat B, Granda TG: Persistent twenty-four hour changes in liver and bone marrow despite suprachiasmatic nuclei ablation in mice. Am J Physiol Regul Integr Comp Physiol 2004, 287:R844-R851.

22. Hunt T, Sassone-Corsi P: Riding tandem: circadian clocks and the cell cycle. Cell 2007, 129:461-464

23. Ma D, Panda S, Lin JD: Temporal orchestration of circadian autophagy rhythm by C/EBPß. EMBO J 2011, 30:4642-4651.

24. Mazzoccoli G, Sothern RB, Greco A, Pazienza V, Vinciguerra M, Liu S, Cai Y: Time-related dynamics of variation in core clock gene expression levels in tissues relevant to the immune system. Int J Immunopathol Pharmacol 2011, 24:869-879.

25. Vinciguerra M, Borghesan M, Pazienza V, Piepoli A, Palmieri O, Tarquini R, Tevy MF, De Cata A, Mazzoccoli G: The transcriptional regulators, the circadian clock and the immune system. J Biol Regul Homeost Agents 2013, 27:9-22.

26. Tevy MF, Giebultowicz J, Pincus Z, Mazzoccoli G, Vinciguerra M: Aging signaling pathways and circadian clock-dependent metabolic derangements. Trends Endocrinol Metab 2013, 24:229-237.

27. Panda S, Antoch MP, Miller BH, Su Al, Schook AB, Straume M, Schultz PG, Kay SA, Takahashi JS, Hogenesch JB: Coordinated transcription of key pathways in the mouse by the circadian clock. Cell 2002, 109:307-320

28. Hughes ME, DiTacchio L, Hayes KR, Vollmers C, Pulivarthy S, Baggs JE, Panda S, Hogenesch JB: Harmonics of circadian gene transcription in mammals. PLoS Genet 2009, 5:e1000442.

29. Bozek K, Relógio A, Kielbasa SM, Heine M, Dame C, Kramer A, Herzel H: Regulation of clock-controlled genes in mammals. PLoS One 2009, 4:e4882.

30. Sukumaran S, Almon RR, DuBois DC, Jusko WJ: Circadian rhythms in gene expression: Relationship to physiology, disease, drug disposition and drug action. Adv Drug Deliv Rev 2010, 62:904-917.
31. Carstea ED, Morris JA, Coleman KG, Loftus SK, Zhang D, Cummings C, Gu J, Rosenfeld MA, Pavan WJ, Krizman DB, Nagle J, Polymeropoulos MH, Sturley SL, loannou YA, Higgins ME, Comly M, Cooney A, Brown A, Kaneski CR, Blanchette-Mackie EJ, Dwyer NK, Neufeld EB, Chang TY, Liscum L, Strauss JF 3rd, Ohno K, Zeigler M, Carmi R, Sokol J, Markie D, O'Neill RR, van Diggelen OP, Elleder M, Patterson MC, Brady RO, Vanier MT, Pentchev PG, Tagle DA: Niemann-Pick C1 disease gene: homology to mediators of cholesterol homeostasis. Science 1997, 277:228-231.

32. Harzer K, Massenkeil G, Frohlich E: Concurrent increase of cholesterol, sphingomyelin and glucosylceramide in the spleen from non-neurologic Niemann-Pick type $C$ patients but also patients possibly affected with other lipid trafficking disorders. FEBS Lett 2003, 537:177-181.

33. Pizarro A, Hayer K, Lahens NF, Hogenesch JB: CircaDB: a database of mammalian circadian gene expression profiles. Nucleic Acids Res 2013, 41:D1009-D1013.

34. Balsalobre A, Damiola F, Schibler U: A serum shock induces circadian gene expression in mammalian tissue culture cells. Cell 1998, 93:929-937.

35. Castellana S, Mazza T: Congruency in the prediction of pathogenic missense mutations: state-of-the-art web-based tools. Brief Bioinform 2013 [Epub ahead of print].

36. Castellana S, Romani M, Valente EM, Mazza T: A solid quality-contro analysis of AB SOLiD short-read sequencing data. Brief Bioinform 2012 [Epub ahead of print].

37. Wasserman S, Faust K: Social Network Analysis: Methods and Applications. Cambridge, UK: Cambridge University Press; 1994.

38. Mazza T, Romanel A, Jordán J: Estimating the divisibility of complex biological networks by sparseness indices. Brief Bioinformatics 2010 , 11:364-374.

39. Mazza T, Ballarini P, Guido R, Prandi D: The relevance of topology in parallel simulation of biological networks. IEEE/ACM Trans Comput Biol Bioinform (TCBB) 2012, 9:911-923.

40. Mazzoccoli G, Pazienza V, Vinciguerra M: Clock genes and clock controlled genes in the regulation of metabolic rhythms. Chronobiol Int 2012, 29:227-251.

41. Kondratov RV, Antoch MP: Circadian proteins in the regulation of cell cycle and genotoxic stress responses. Trends Cell Biol 2007, 17:311-317.

42. Doi M, Hirayama J, Sassone-Corsi P: Circadian regulator CLOCK is a histone acetyltransferase. Cell 2006, 125:497-508.

43. Ukai-Tadenuma M, Yamada RG, Xu H, Ripperger JA, Liu AC, Ueda HR: Delay in feedback repression by cryptochrome 1 is required for circadian clock function. Cell 2011, 144:268-281.

44. Fustin JM, O'Neill JS, Hastings MH, Hazlerigg DG, Dardente H: Cry1 circadian phase in vitro: wrapped up with an E-box. J Biol Rhythms 2009 24:16-24.

45. Agostino PV, Harrington ME, Ralph MR, Golombek DA: Casein kinase- 1 -epsilon (CK1epsilon) and circadian photic responses in hamsters. Chronobiol Int 2009, 26:126-133.

46. Burris TP: Nuclear hormone receptors for heme: REV-ERBalpha and REV-ERBbeta are ligand-regulated components of the mammalian clock. Mol Endocrinol 2008, 22:1509-1520.

47. Tahara Y, Otsuka M, Fuse Y, Hirao A, Shibata S: Refeeding after fasting elicits insulin-dependent regulation of Per2 and Rev-erba with shifts in the liver clock. J Biol Rhythms 2011, 26:230-240.

48. Raspe' E, Duez H, Mansen A, Fontaine C, Fievet C, Fruchart JC, Vennstrom B, Staels B: Identification of Rev-erb alpha as a physiological repressor of apoC-III gene transcription. J Lipid Res 2002, 43:2172-2179.

49. Asher G, Gatfield D, Stratmann M, Reinke H, Dibner C, Kreppel F, Mostoslavsky R, Alt FW, Schibler U: SIRT1 regulates circadian clock gene expression through PER2 Deacetylation. Cell 2008, 134:317-328.

50. Guarente L, Franklin H: Epstein lecture: Sirtuins, aging, and medicine N Engl J Med 2011, 364:2235-2244.

51. Zhao W, Kruse JP, Tang Y, Jung SY, Qin J, Gu W: Negative regulation of the deacetylase SIRT1 by DBC1. Nature 2008, 451:587-590.

52. Brooks CL, Gu W: How does SIRT1 affect metabolism, senescence and cancer? Nat Rev Cancer 2009, 9:123-128.

53. Schoenhard JA, Smith LH, Painter CA, Eren M, Johnson CH, Vaughan DE: Regulation of the PAI-1 promoter by circadian clock components: differential activation by BMAL1 and BMAL2. J Mol Cell Cardiol 2003, 35:473-481.

54. Cermakian N, Lange T, Golombek D, Sarkar D, Nakao A, Shibata S, Mazzoccoli G: Crosstalk between the circadian clock circuitry and the immune system Chronobiol Int 2013:1-19. DOl: 10.3109/07420528.2013.782315. 
55. Lindsey S, Papoutsakis ET: The evolving role of the aryl hydrocarbon receptor (AHR) in the normophysiology of hematopoiesis. Stem Cell Rev 2012, 8:1223-1235

56. Narasimamurthy R, Hatori M, Nayak SK, Liu F, Panda S, Verma IM: Circadian clock protein cryptochrome regulates the expression of proinflammatory cytokines. Proc Natl Acad Sci USA 2012, 109:12662-12667.

57. Chu TJ, Peters DG: Serial analysis of the vascular endothelial transcriptome under static and shear stress conditions. Physiol Genomics 2008, 34:185-192.

58. Anderson G, Beischlag TV, Vinciguerra M, Mazzoccoli G: The circadian clock circuitry and the AHR signaling pathway in physiology and pathology. Biochem Pharmacol 2013. doi:pii: S0006-2952(13)00126-3. 10.1016/j. bcp.2013.02.022. [Epub ahead of print].

59. Zhang N, Walker MK: Crosstalk between the aryl hydrocarbon receptor and hypoxia on the constitutive expression of cytochromeP4501A 1 mRNA. Cardiovasc Toxicol 2007, 7:282-290

60. Chilov D, Hofer T, Bauer C, Wenger RH, Gassmann M: Hypoxia affects expression of circadian genes PER1 and CLOCK in mouse brain. FASEB $J$ 2001, 15:2613-2622

61. Santilli G, Lamorte G, Carlessi L, Ferrari D, Rota Nodari L, Binda E, Delia D, Vescovi AL, De Filippis L: Mild hypoxia enhances proliferation and multipotency of human neural stem cells. PLoS One 2010, 5:e8575.

62. Oliveira SA, Li YJ, Noureddine MA, Zuchner S, Qin X, Pericak-Vance MA, Vance JM: Identification of risk and age-at-onset genes on chromosome $1 p$ in Parkinson disease. Am J Hum Genet 2005, 77:252-264.

63. Ohlenbusch A, Henneke M, Brockmann K, Goerg M, Hanefeld F, Kohlschütter A, Gärtner J: Identification of ten novel mutations in patients with elF2B-related disorders. Hum Mutat 2005, 25:411.

64. Scali O, Di Perri C, Federico A: The spectrum of mutations for the diagnosis of vanishing white matter disease. Neurol Sci 2006, 27:271-277.

doi:10.1186/1755-8794-6-37

Cite this article as: Mazzoccoli et al:: Circadian transcriptome analysis in human fibroblasts from Hunter syndrome and impact of iduronate-2sulfatase treatment. BMC Medical Genomics 2013 6:37.

\section{Submit your next manuscript to BioMed Central and take full advantage of:}

- Convenient online submission

- Thorough peer review

- No space constraints or color figure charges

- Immediate publication on acceptance

- Inclusion in PubMed, CAS, Scopus and Google Scholar

- Research which is freely available for redistribution

Submit your manuscript at www.biomedcentral.com/submit
C Biomed Central 